\title{
Visualizing Teacher Education as a Complex System: A Nested Simplex System Approach
}

\author{
LARRY LUDLOW ${ }^{1}$, FIONA ELL ${ }^{2}$, MARILYN COCHRAN-SMITH ${ }^{1}$, AVERY NEWTON ${ }^{1}$, \\ KAITLIN TREFCER ${ }^{1}$, KELSEY KLEIN ${ }^{1}$, LEXIE GRUDNOFF ${ }^{2}$, MAVIS HAIGH ${ }^{2}$ \& MARY F. \\ HILL $^{2}$ \\ ${ }^{1}$ Boston College (USA) \\ ${ }^{2}$ The University of Auckland (New Zealand)
}

\begin{abstract}
Our purpose is to provide an exploratory statistical representation of initial teacher education as a complex system comprised of dynamic influential elements. More precisely, we reveal what the system looks like for differently-positioned teacher education stakeholders based on our framework for gathering, statistically analyzing, and graphically representing the results of a unique exercise wherein the participants literally mapped the system as they perceived it. Through an iterative series of inter-related studies employing cluster analysis and multidimensional scaling procedures, we demonstrate how initial teacher education may be represented as a complex system comprised of interactive agents and attributes whose perceived relationships are a function of nested stakeholder-dependent simplex systems. Furthermore, we illustrate how certain propositions of complexity theory, such as boundaries, heterogeneity, multidimensionality and emergence, may be investigated and represented quantitatively.
\end{abstract}

\section{Introduction}

How teachers ought to be recruited, prepared, and evaluated is contested not only by those who are involved in providing initial teacher education (Kumashiro, 2015), but also by outside critics who assume teacher preparation is a straightforward process that leads directly to desired school outcomes (U.S. Department of Education, 2009; Hess \& McShane, 2014). One approach to understanding the aspects of teacher preparation that positively influence student outcomes has been to simplify the problem by focusing on key parts of initial teacher preparation programs or policies without necessarily considering how these parts influence and are influenced by other factors (Cochran-Smith \& Fries, 2005; Cochran-Smith \& Villegas, 2014). However, many scholars have concluded that teacher education research needs to take a complex view, resist 
simplification, and account more fully for teacher education's intersecting contexts and processes (e.g., Cochran-Smith \& Zeichner, 2005; Cochran-Smith, Ell, Ludlow, Grudnoff \& Aitken, 2014; Grossman \& McDonald, 2008; Opfer \& Pedder, 2011).

The present investigation rests on the assumption that initial teacher education (ITE) may be understood as a complex system (Davis \& Sumara, 1997; Reynolds, 2011; Waks, 2011), an idea to which we return below. The purpose of this paper is to provide a statistical graphical interpretation of what that system "looked like" for differently-positioned teacher education stakeholders, including teacher candidates, mentor teachers, teacher educators, and policy makers. We do this by presenting a framework for gathering, statistically analyzing, and graphically representing a unique data set wherein the participants constructed "maps" of the initial teacher education (ITE) system as they perceived it. We then discuss how different treatments of the data and subsequent modes of analysis reveal differences in the ways the nature and structure of the system were understood and represented by the different stakeholders. Throughout this framework of exploration and interpretation we illustrate how certain fundamental propositions of complexity theory may be framed, investigated and represented quantitatively.

Our paper moves through five successively more detailed phases of investigation analogous in a certain way to peeling off the layered leaves of an artichoke. Each phase employed different forms of data and quantitative procedures with their own strengths, limitations and findings while explicitly building upon the previous ones. For ease of communication we refer to these phases as "studies." The first study investigated participants' perceptions of the strength of influence various system elements had on teacher candidates' learning to teach in ways that promoted all children's learning. The second investigated the extent to which those elements formed meaningful clusters of similarly perceived sources of influence while the third investigated how those clusters were related to one another. The fourth study builds on the previous phases to develop the notion of multi-dimensional "system consensus maps." These consensus maps represent graphically how participants' perceptions of element influences, interactions, and clustering patterns differ by stakeholder group but, more importantly as we show in detail below, the consensus maps are presented as stakeholderdependent simplex system representations (i.e., simplifying representations of an overarching complex system) (Van Geert and Steenback, 2014). In the fifth study the group-level consensus maps are combined to form a meta-complex system representation comprised of intersecting system elements and attributes whose perceived relationships are dependent upon one's membership within a given group-level simplex system representation. These studies all draw upon the same mapping task to generate differing, yet complementary and successively deeper, quantitative representations of how a complex social system may be understood.

\section{Theoretical Framework and Project RITE}

The present program of research on initial teacher education was carried out by the members of Project RITE (Rethinking Initial Teacher Education for Equity), a two-country research project led by researchers and practitioners at the University of Auckland in New Zealand and Boston College in the United States. One fundamental premise underlying the overall work of Project 
RITE is that initial teacher education occurs within and across intersecting complex systems and communities, including individuals, schools, preparation programs, policy environments, and larger social systems.

In a review of research about experienced teachers' learning, Opfer and Pedder (2011) argued that professional development for teachers (and, we would add, teacher candidates) is often ineffective because it is driven by an underlying process-product logic (historically instantiated as correlational studies investigating the relationships between teacher behaviors and desired outcomes, particularly student learning). This kind of logic does not acknowledge that teachers' learning is deeply embedded in their professional lives and in complex school working conditions. Instead of simplifying, Opfer and Pedder proposed that teacher learning should be conceptualized in terms of overlapping complex systems with the goal of developing a complex explanatory theory based on patterns of interaction within and between levels of system activity. Following Opfer and Pedder (2011), the RITE group aimed to develop a framework for research on initial teacher education that could account for the complexity of teaching, learning, schooling, and inequality and could, over time, allow us to examine how the "causal" or "generative" mechanisms of teacher learning occurred under varying conditions and contexts. We have described our still-developing theoretical framework in detail in two recent articles (Cochran-Smith, Ell, Ludlow, Grudnoff \& Aitken, 2014; Cochran-Smith, Ell, Grudnoff, Ludlow, Haigh \& Hill, 2014); thus we provide only a brief overview here.

Many philosophers and educators have explored complexity theory, including its power and challenges as a framework for education research (e.g., Davis, Phelps \& Wells, 2004; Davis \& Sumara, 1997, 2006, 2007, 2010; Haggis, 2008; Mason, 2008; Morrison, 2008; Radford, 2006; Pratt, 2011; Sumara \& Davis, 1997, 2009; Waks, 2011). One of the key ideas in discussions of complexity theory and education, which is particularly relevant to the investigation reported in this article, is that many aspects of education, including individuals (e.g., teachers, students, teacher educators), classrooms, schools, teacher education programs, professional learning contexts, and mentoring relationships, can be understood as complex systems (e.g., Clarke \& Erickson, 2009; Davis, Sumara \& D'Amour, 2012; Fels, 2004; Nielson, Triggs, Clarke \& Collins, 2010; Opfer \& Pedder, 2011; Radford, 2006; Schneider \& Somers, 2006; Waks, 2011).

Although there are many aspects of complexity theory that have been widely written about, we limit our discussion to those aspects for which our framework of data collection and analysis is most suited and which we are able to illustrate. For example, complex systems are nested within, and intersect with, other systems (Byrne, 1998; Houchin \& MacClean, 2005; Mason, 2008; Waks, 2011). Acknowledging nested systems, however, does not necessarily imply an ordered hierarchical structure (Byrne \& Callaghan, 2014). Rather within nested systems there may be sub-systems of communities of individuals with their own "simplex systems" (Van Geert \& Steenbeck, 2014) of element structures and relationships dependent upon their individual perceptions of salient aspects of the broader system under consideration and the ways these are enmeshed within shared systems. Van Geert and Steenbeck (2014) define a simplex system as "a connected whole of beliefs, representations, values, emotions, habits, practices and material tools that serves as a simplifying representation of the overarching complex system in which a person participates and that organizes the participants' actions" (p. 23). 
These systems necessarily represent inter-individual differences between groups of people and intra-individual differences within groups (Van Geert \& Steenbeck, 2014). The differences within groups are then a specific form of statistical heterogeneity described within complexity theory as "multifinality" (similar experiences that may lead to dissimilar outcomes) (George \& Bennett, 2005).

Complex systems, including simplex systems, change and over time new patterns of interactive relationships emerge; hence systems are always in a state of emergence (Byrne, 1998; Cilliers, 1998; Davis \& Sumara, 2006; Haggis, 2008; Morrison, 2008). When studying longitudinal emergence the appropriate level of measurement has been described as nonmetric, usually referring to ordinal relations but also nominal, where the study of change, or emergence, is described as one of differences in kind not degree (Byrne \& Callaghan, 2014). Instead of predictable linear effects, then, complexity theory emphasizes that ever-changing multi-dimensional relationships, shifting boundaries of influences, and dynamic interactions among agents and elements over time are responsible for unpredictable non-linear changes in patterns and phenomena (Byrne \& Callaghan, 2014). A key idea here for teacher education research is that understanding multiple, complex, and contingent causality depends on deep understandings of local initial conditions and sequences of transformative events, all linked to larger understandings of processes and outcomes at various intersecting system levels (Byrne \& Callaghan, 2014).

\section{Methods}

Although complexity theories do not yet offer a package of methods for data gathering and analysis (Haynes, 2008; Schneider \& Somers, 2006), we have found that a complexity theory framework suggests some important possibilities for research methods and designs, including system mapping. As we mean it here, system mapping is both a method of data collection and a tool for data analysis. In short, our system mapping application is a suite of tools intended to lay out the general landscape of a complex system, including its major elements and structures, its interdependencies and overlapping areas, and its ambiguous boundaries. Of course no single participant in a complex system can fully perceive the system because each participant knows primarily the elements and processes that are closest to him or her. Hence, each person has his or her own perspective regarding the nature and functioning of the system. This means that constructing an overall sense of initial teacher education as a system requires garnering and creatively combining many different viewpoints.

For the present investigation, we aimed to get at participants' understandings of initial teacher education conceptualized as a system by developing a system mapping task. Through this task we considered the following Research Questions (RQ).

RQ1: What elements (actors and structures) do participants think about when they consider what defines the important components of teacher education?

RQ2: What do they perceive as the strength of influence of these elements on teacher candidates' learning?

RQ3: How do they perceive the interactions among and links between these elements? 
RQ4: What does a multi-dimensional "consensus map" graphical representation reveal about the perceptions and experiences of participants within stakeholder groups?

RQ5: Finally, how can group-specific simplex system representations be used to portray system change and emergence over time?

These five questions are addressed in the studies reported below.

\section{Study participants}

The participants in this study were drawn from the three-year program leading to a Bachelor of Education (Teaching) qualification at the University of Auckland, Auckland, Aotearoa New Zealand. There were approximately 1200 teacher candidates in the program who were being prepared to teach in primary schools serving children between 5 and 12 years of age. The program's mission is to prepare teachers who work effectively with all students by building on children's differing cultural, linguistic, and socio-economic backgrounds and recognizing diverse educational needs.

Study participants included: teacher candidates from the BEd (Teaching) program, teacher educators of the Faculty of Education at the University of Auckland, experienced mentor teachers from practicum schools, and a small group of national-level teacher education policy makers. Approximately 250 second-year teacher candidates were eligible to participate and all of them were invited by email once ethics approval had been gained from the university's human participants ethics committee. Twenty eight teacher candidates responded to the invitation, with 23 completing the mapping task. Twenty-five teacher education academics, 25 mentor teachers, and three national teacher education policy makers also participated.

Because the present paper concentrates on the development of a complexity system data collection, analysis and interpretation methodology, we use only the teacher candidate and teacher educator data to illustrate the procedures and the complexity concepts they address, i.e. we do not include the mentor teacher and policy maker data. This emphasis upon the teacher candidates and teacher educators is not simply one of convenience. Rather this choice presents an opportunity to investigate longitudinal change and system transformation, or emergence. That is, the teacher candidates in the study were just beginning their teaching careers and their experiences with the initial teacher preparation system were necessarily limited. In contrast the teacher educators started off as teacher candidates who then graduated and took teaching positions, and many served as mentor teachers before moving into their university positions. Their experiences with the system were thus much broader than the teacher candidates' and their perceptions of the elements that influence teaching were shaped by years of engagement with teacher preparation programs and processes. This means that even if some or many of the elements in the system are the same for teacher candidates and teacher educators, the relationships among the elements and their relative influence, and consequently the nature and structure of the system, may be perceived by the teacher educators in substantively different ways as a result of individual adaptations to system constraints and opportunities encountered over time. This suggests, as we show and argue later, that there may be no single definition and representation of " $a$ " teacher education system.

\section{Mapping task}




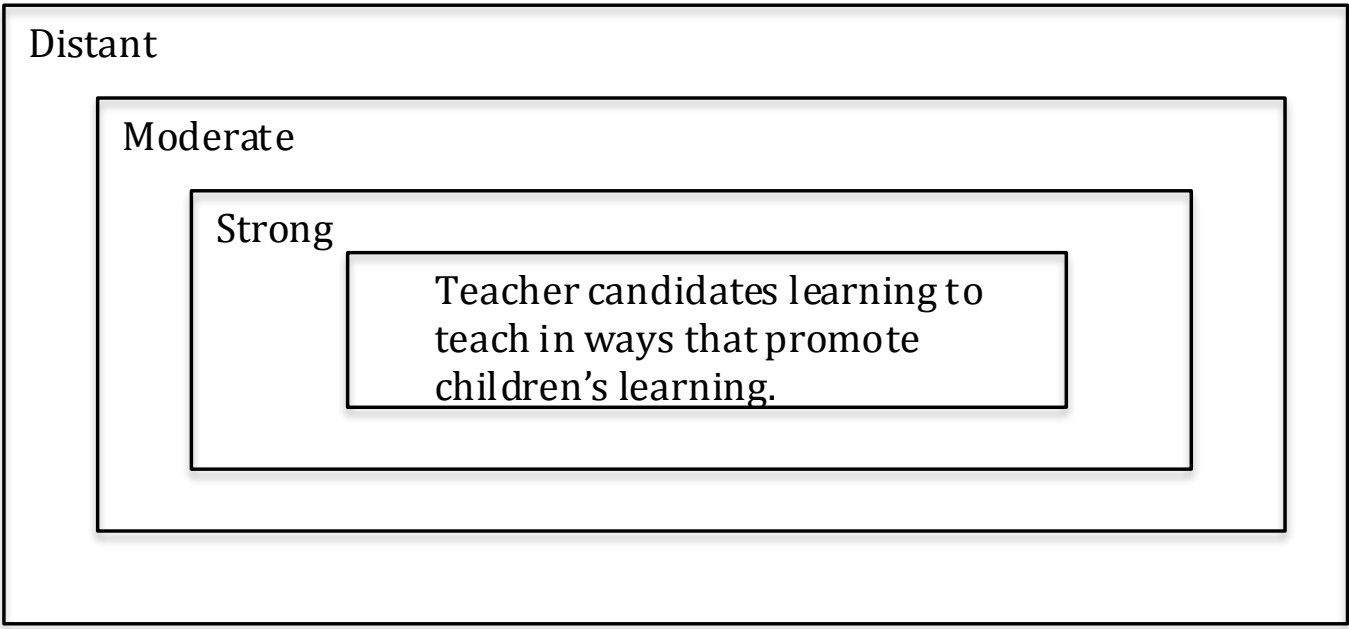

Figure 1: Teacher education system mapping task

Given that we conceptualized teacher education as a complex and flexible system of dynamic connections between and among actors and structures that continuously change over time, we needed a research design that would capture these conditions. For our studies we drew on network and systems theory strategies (e.g., Davis, Sumara \& D'Amour, 2012; Kowch, 2012) to develop a system mapping task and then borrowed ideas from concept mapping about how to adjust and reduce the demands of the task (Ruiz-Primo \& Shavelson, 1996).

"Teacher candidates learning to teach in ways that promote children's learning" was selected as the focal point of the mapping task because this is the outcome the overall project is interested in achieving. We specifically wanted to know how different stakeholder groups within the teacher education system perceived the influence of various system elements and their relationships on this outcome.

The mapping task was developed iteratively during a series of small pilot studies. Initially, the task was open-ended. The participants were simply given a large blank sheet of paper and asked to (a) identify elements (i.e., people and things) that they believed influenced teacher candidates' learning to teach in ways that promoted children's learning, and (b) arrange the elements on the paper in some configuration that represented the elements' relative influence and their inter-connections. Not surprisingly, the pilot participants indicated that the openended nature of this task was daunting.

To reduce task demand, we introduced some constraints. First we provided a sheet of paper with a set of concentric rectangles intended to represent levels of influence and labeled these as "strong", "moderate" and "distant" (Figure 1). This diagram became the basis of the "map" each participant created. Then participants were given a list of 37 possible teacher education system elements from which they could select to place on the map (Table 1). The "people" category referred to people and the roles of various people, such as school principals and student teachers (also referred to as "teacher candidates"), and friends and family, as well as aspects or qualities of people, such as personal beliefs and values. The "things" category included social and organizational structures related to the program, such as the practicum 


\begin{tabular}{|c|c|c|c|}
\hline Visiting Lecturer & $\mathrm{v} 1$ & Media Coverage & v20 \\
\hline Other Student Teachers & $\mathrm{v} 2$ & $\begin{array}{l}\text { Professional } \\
\text { development in } \\
\text { school }\end{array}$ & $\mathrm{v} 21$ \\
\hline $\begin{array}{l}\text { Personal } \\
\text { Circumstances }\end{array}$ & v3 & $\begin{array}{l}\text { Ministry of } \\
\text { education }\end{array}$ & v22 \\
\hline Prior Experiences & $\mathrm{v} 4$ & $\begin{array}{l}\text { Practicum } \\
\text { supervision }\end{array}$ & v23 \\
\hline $\begin{array}{l}\text { Mentor teacher in } \\
\text { school }\end{array}$ & v5 & $\begin{array}{l}\text { Assessment } \\
\text { Processes }\end{array}$ & $\mathrm{v} 24$ \\
\hline Friends and Family & v6 & Teachers council & v25 \\
\hline $\begin{array}{l}\text { Parents and Whānau of } \\
\text { practicum school }\end{array}$ & v7 & National standards & $\mathrm{v} 26$ \\
\hline $\begin{array}{l}\text { Practicum } \\
\text { Administrator }\end{array}$ & v8 & Course teaching & $\mathrm{v} 27$ \\
\hline Principal & v9 & Library & v28 \\
\hline Adjunct Lecturer & v10 & $\begin{array}{l}\text { University-school } \\
\text { partnerships }\end{array}$ & v29 \\
\hline Children in classroom & $\mathrm{v} 11$ & Practicum office & v30 \\
\hline $\begin{array}{l}\text { Teaching Colleagues in } \\
\text { Practicum School }\end{array}$ & $\mathrm{v} 12$ & Exams & v31 \\
\hline Lecturers & v13 & $\begin{array}{l}\text { Graduating teacher } \\
\text { standards }\end{array}$ & v32 \\
\hline Researchers & v14 & $\begin{array}{l}\text { Academic success } \\
\text { centre }\end{array}$ & v33 \\
\hline $\begin{array}{l}\text { Personal Beliefs and } \\
\text { Values }\end{array}$ & $\mathrm{v} 15$ & Practicum school & v34 \\
\hline Prior Knowledge & v16 & Portfolio & v35 \\
\hline $\begin{array}{l}\text { Prior Experience as a } \\
\text { Learner }\end{array}$ & $\mathrm{v} 17$ & Assignments & 36 \\
\hline $\begin{array}{l}\text { Leaders of the Teacher } \\
\text { Education Programme }\end{array}$ & v18 & $\begin{array}{l}\text { Social Media } \\
\text { groups }\end{array}$ & v37 \\
\hline $\begin{array}{l}\text { New Zealand } \\
\text { Curriculum }\end{array}$ & v19 & & \\
\hline
\end{tabular}

Table 1: Elements and codes

school, as well as entities and regulations governing teacher preparation, such as the Ministry of Education. This initial list of elements, which was informed by the literature on how candidates learn to teach and the experiences of the teacher education practitioners in the research group, 
was adjusted according to the elements identified by the initial pilot participants who were not given such a list.

These elements define sets of influences from the individuals and their families and friends, the schools where the candidates taught, the university where the candidates were prepared, and external government policies and regulations. We expected that, depending on one's stakeholder status, these sets of elements would be perceived as having intersecting and permeable boundaries relative to one another (Byrne \& Callaghan, 2014) and would be perceived as having different degrees of influence upon teacher candidates' learning to teach in ways that promoted children's learning. Respondents' perceptions of the dynamic nature and influence of these bounded sets then define the teacher education simplex system structure for a given stakeholder group (Van Geert \& Steenbeck, 2014). The analytic and interpretive challenge was to reveal these separate simplex structures with their intersecting and shifting boundaries of influential elements all nested within the broader overarching ITE system.

The mapping instructions were: "We would like you to create a map or diagram that is an explanation of how student teachers learn to teach in ways that promote children's learning. This task is not about explaining what could or should influence how student teachers learn to teach in ways that promote children's learning, but what you believe does explain this learning." The participants were then asked to place people and things within the concentric rectangles using "post-it" note paper labels for each element. They did not have to use all of the elements and were invited to add others if desired. Once elements were placed, they were asked to "draw lines between the people and things to indicate relationships, or if there is a group of elements closely related together then draw a circle around these." Participants could move elements around on the diagram base while they constructed their maps. Each of the 76 participants produced a two-dimensional map with their selected elements placed within the concentric rectangles (see the examples in Figure 2a and Figure 2b). Pink sticky notes were used for people elements and blue sticky notes for things.

\section{Data sources}

We investigated system structures through categorization and frequency count operations but we also illustrate metric measurement and analysis through the unique mapping task that participants performed. Three forms of quantitative data were extracted from the qualitative maps. The first consisted of recording for each map the strength of influence associated with each element: a " 0 " indicated that the element was not on the map, " 1 " that the element was placed in the 'distant' section, " 2 " for elements in the 'moderate' section, and " 3 " for elements in the 'strong' section. Within each stakeholder group, the mean strength of influence was calculated for each element. Cut off points were established for whether the mean for an element indicated a 'strong' (2.5-3), 'moderate' (1.9-2.4) or 'distant' (1-1.8) degree of influence. Elements with averages of less than 1 were deemed 'beyond distant' in their influence. These data were used in Study 1 to address RQ1 and RQ2 regarding the perception of influential elements and their respective degrees of strength.

The second form of data focused on the linkages drawn among the elements. For each of the 76 maps, a 37x37 matrix was constructed with the rows and columns consisting of the 37 possible elements. The cells of the matrix contained a " 1 " if the participant had drawn a line 


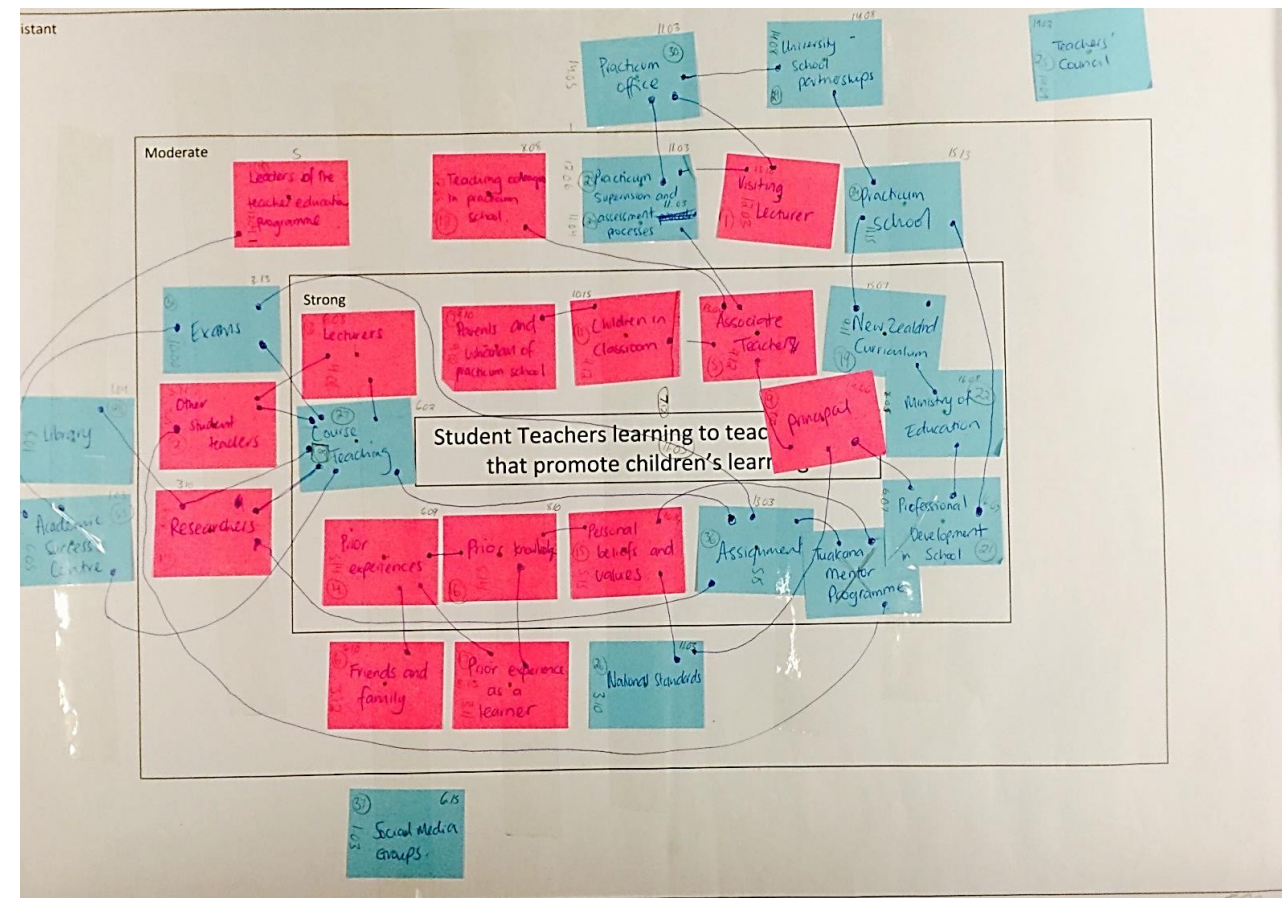

Figure 2a: Example of system map with lines and arrows

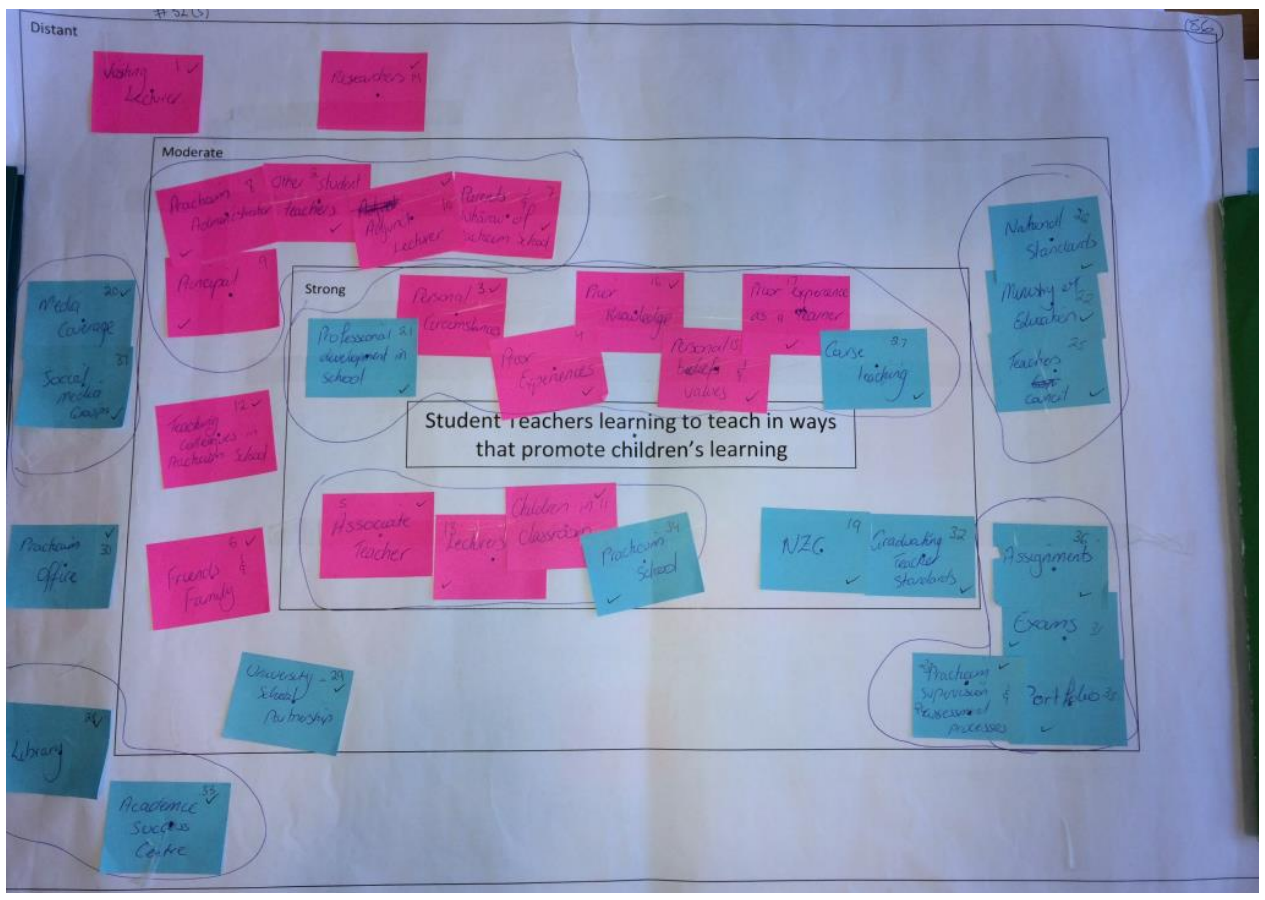

Figure 2b: Example of system map with circles

linking any two of the mapped elements and a " 0 " if there was no drawn link. Then the individual matrices were aggregated into group-level matrices where the cells consisted of the number of times each pairwise combination of elements was linked across all the participants in 
a given group. These data were used in Study 2 and Study 3 to address RQ3 regarding interactions among the influential elements.

The third form of data consisted of pairwise distances among elements with the central box representing teacher candidates' learning now considered an "element." Within each map, we placed a centered mark on each element's sticky-note (visible on the sticky-notes in Figures 2a and $2 b$ ) and physically measured the distance from the element's center to the left edge of the map and then to the bottom edge of the map (each blank map was a duplicate of the original). These measurements defined the horizontal $(X)$ and vertical $(Y)$ Euclidean two-dimensional coordinates for all elements within a map, including the location of the central teacher candidates' learning element. We then wrote a Python computer program that used the coordinate-based input described above to compute the Euclidean distances among all elements. These pairwise distances were then arranged in a distance matrix for each participant for Study 4 and Study 5 to address RQ4 and RQ5 regarding multi-dimensional graphical representations of system structures.

\section{Analytic Framework}

Cluster analysis is ideally suited for revealing the extent to which the elements in a system form interpretable, meaningful clusters of similarly perceived elements (Aldenderfer \& Blashfield, 1984; Everitt, 1974; Lorr, 1983). In addition, multidimensional scaling (MDS) is ideal for revealing the extent to which the links and subsequent clusters are based on some underlying common characteristics (Kruskal \& Wish, 1978; Shepard, Romney \& Nerlove, 1972). Although these characteristics may form orthogonal factors, or independent dimensions, in an ordinary Cartesian coordinate system, they may also show circular, and irregular patterns of arrangements that more descriptively capture how elements form clusters and then how clusters form substantively meaningful patterns (Kruskal \& Wish, 1978). Depending on the nature of the research question, the focus of the analysis may either be on exploring dimensions of common characteristics (as in Study 3) or patterns of non-linear relationships (Study 4).

These two statistical approaches are consistent within our complexity framework since our intention was to explore, discover and interpret multidimensional relationships among the actors and structures in our mapping task. Furthermore, these procedures are capable of showing differences between groups and changes in patterns over time. Multidimensional scaling has the added benefit of being able to reveal within-group heterogeneity, i.e. individual differences and outlier patterns that deviate from a group's consensus pattern of element relationships.

The main value of these two statistical procedures, for us, is their exploratory power to reveal underlying relationships that participants may have either consciously or unconsciously relied upon when they considered how the elements in the system were related to one another and to teacher candidates' learning to teach all students, which was at the center of the map representing the goal of the teacher education program. By performing our analyses across individual distance matrices, the cluster analysis and MDS procedures, particularly when employed together, generate visual representations of group-level "consensus system maps," each of which is composed of different configurations of inter-connected individual, school, 
university and policy elements all with differing boundaries and degrees of influence on learning to teach in ways that promote children's learning. These consensus system maps then serve as visual representations of Van Geert and Steenbeck's (2104) simplex system structures.

\section{Cluster Analysis}

When applying cluster analysis to a distance matrix, an initial cluster is formed from the two closest elements where "close" is usually based on the Euclidean distances between pairs of elements. Subsequent clusters are formed (depending on various analytic options) through an agglomeration process of combining simple groupings of elements into larger groupings. This iterative process continues until every element in the distance matrix has been brought into the cluster solution.

Statistical classification of elements into clusters, based on the particular option selected, is relatively straightforward, but the interpretive meaning of a cluster is more subjective since more than one reasonable argument can usually be made for smaller or larger cluster formations. That is, with an agglomerative process, there are legitimate questions about the point at which the analyst decides that the homogeneity of elements already within a cluster is threatened by the inclusion of additional elements and the additional elements should therefore be considered as forming their own cluster. Hence, the specification of the "correct" number and composition of clusters ultimately depends on an understanding of the clustering options, the degree of commonality of the elements that have been combined statistically, and how that cluster has substantive meaning, if any.

\section{Multidimensional Scaling}

The ALSCAL (Alternating Least Squares Scaling) (Takane, Young \& de Leeuw, 1977) MDS procedure provides a highly adaptable set of analysis options (Version: IBM SPSS Statistics 22). Using either a single matrix (for an individual) or multiple matrices (for everyone within a group), ALSCAL analyzes the Euclidean distances among all elements and generates a statistical re-expression of the elements' relationships that best reproduces the original distances that were contained in the individual participant maps (e.g., Figures $2 a$ and $2 b$ ). The subsequent graphical output reveals details about these element relationships and linkages, subsequent cluster formations, and underlying dimensions, or patterns, of similarity and dissimilarity. Even though the mapping task requires participants to place system elements within a twodimensional physical arrangement, the statistical description of an underlying common structure uniting the elements both within groups and across groups may reveal three or more dimensions of common characteristics, that participants were presumably considering when they performed the mapping task.

The MDS procedure generates axis-based dimensions from strongest to weakest-similar to traditional factor analysis approaches (Thurstone, 1947). The key to understanding the results is the extent to which meaning may be made of the arrangement of the elements, their apparent cluster compositions, and the arrangement of the clusters to one another thereby defining the substantive meaning of dimensions and patterns. There are statistical indicators of goodness-offit (e.g., stress and R2 [Kruskal \& Wish, 1978]) that assist in the determination of numbers of clusters and dimensions, but these indicators are easily influenced by data exhibiting great 
variability and heterogeneity in responses and the extent of missing data (elements which may not have been used by a participant) - which is the situation with the present data as will become apparent. Hence, determination of the "right" numbers of clusters and dimensions and their subsequent interpretation is necessarily a subjective exercise based on experience with the methods and familiarity with the initial teacher education context.

The IBM SPSS Statistics 22 syntax code for one set of cluster and MDS analyses conducted on the linkages (for Study 2 and Study 3) is presented in the Appendix, sections a-b. The corresponding code executed upon the distances (for Study 4 and Study 5) is presented in the Appendix, sections c- $d$. Note that the elements are generically referred to as variables and are identified as 1- 37 with the prefix "v." For Study 4 and Study 5 the first entry in the distance matrices is the teacher candidates' learning to teach all students location (TC). Table 1 includes the identifiers for v1-v37.

\section{Understanding Initial Teacher Education as a System: A Suite of Mapping Studies}

\section{Study 1}

The purpose of Study 1 was to investigate what elements differently-positioned participants thought were influential and the strength to which they perceived those elements were influential on teacher candidates' learning to teach in ways that promote children's learning (RQ1, RQ2). The number of elements used by participants ranged from 14 to 37 with the average number of elements varying according to participant group: teacher candidates used 28 elements, mentor teachers 30 elements, policy makers 31 elements, and teacher educators 35 elements. Table 2 summarizes major similarities and differences across the participants' perceptions of the elements that had a strong influence on teacher candidates learning to teach.

Comparing the perceptions of the four stakeholder groups reveals two striking patterns. First, although the teacher candidates identified only three strong influences while the other groups identified more than three out of the 37 listed, all four groups identified the same three elements as having a strong influence: teacher candidates' personal beliefs and values, mentor teachers, and the children in classrooms. Second, and more significant for our purposes, there is a difference between the teacher candidates and teacher educators, which can be interpreted as a consequence of changing experiences and perceptions over time. Specifically, in addition to maintaining the same appreciation for the three elements emphasized by the teacher candidates as they start teaching (suggesting that the educators would have emphasized these elements when they were candidates many years earlier), the teacher educators also see school and university elements as influential in ways the candidates have not yet come to appreciate. Although early in our analysis, the educator perceptions of the system appear broader, more interactive, and more flexible than those of the candidates - and these observations are explored more deeply in the later studies.

These results may be useful for teacher educators involved in decisions about teacher education curriculum and local policy (Ell et al., in press), but they do not fully capture the nature and intent of the mapping task. That is, a nominal classification table format does not 


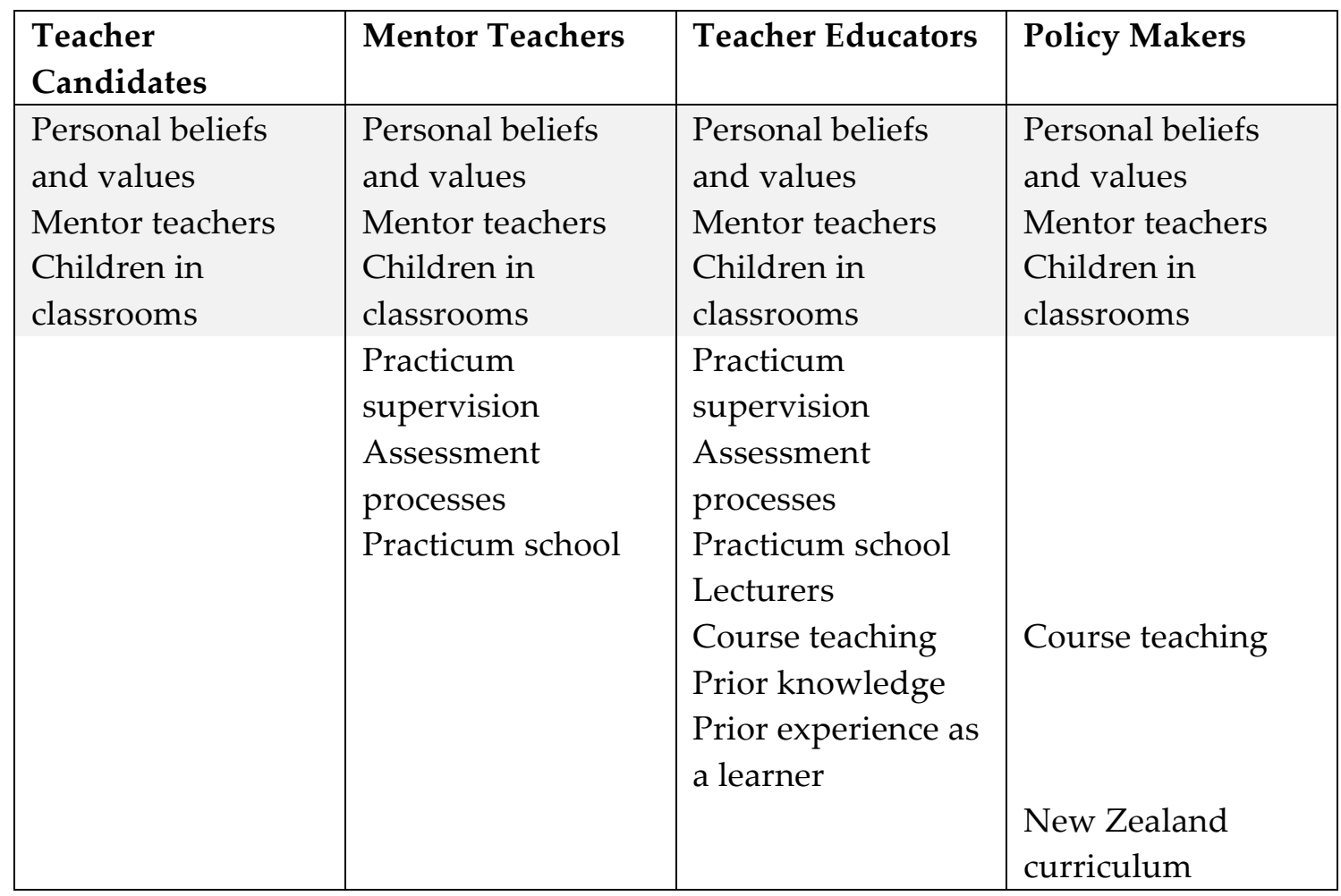

Table 2: Teacher education system elements with strong influence on average, by constituency group

provide a graphical representation that re-expresses the maps in a way that shows what the overall system looks like with the various elements linked together in a two-dimensional space. This limitation raises questions of both methodology and interpretation. For example, are Figures $2 \mathrm{a}$ and $2 \mathrm{~b}$ simply illustrative exemplars for all the maps that were constructed, or do Figures $2 a$ and $2 b$ represent a baseline foundation for the construction of a "consensus map" perspective for all those people in the groups from which they were selected?

\section{Study 2}

The purpose of Study 2 was to investigate the element linkages (RQ3). We obtained the average number of linkages for all the $(37 \times(37-1)) / 2$ pairs of links and rank ordered the pairs of elements from most-to-least links for each group. This simple linear analysis confirmed the findings in Study 1 that the teacher educators had higher linkage counts than the candidates. More importantly, however, we framed the linkages as proximity measures that represent a form of similarity, or closeness, between each pairing of elements. That is, in a geometric sense, the more links that are drawn between two elements for the set of maps within a particular group, the closer the distance is between those two elements.

By employing the SPSS PROXIMITIES procedure we converted the frequency counts of the pairwise linkages into phi-square statistics (Version: IBM SPSS Statistics 22) for the subsequent CLUSTER procedure. We selected the single-linkage agglomeration clustering option to iteratively combine the closest linked elements into increasingly larger clusters. The agglomeration steps are portrayed as a "dendrogram" that shows at each step which elements 


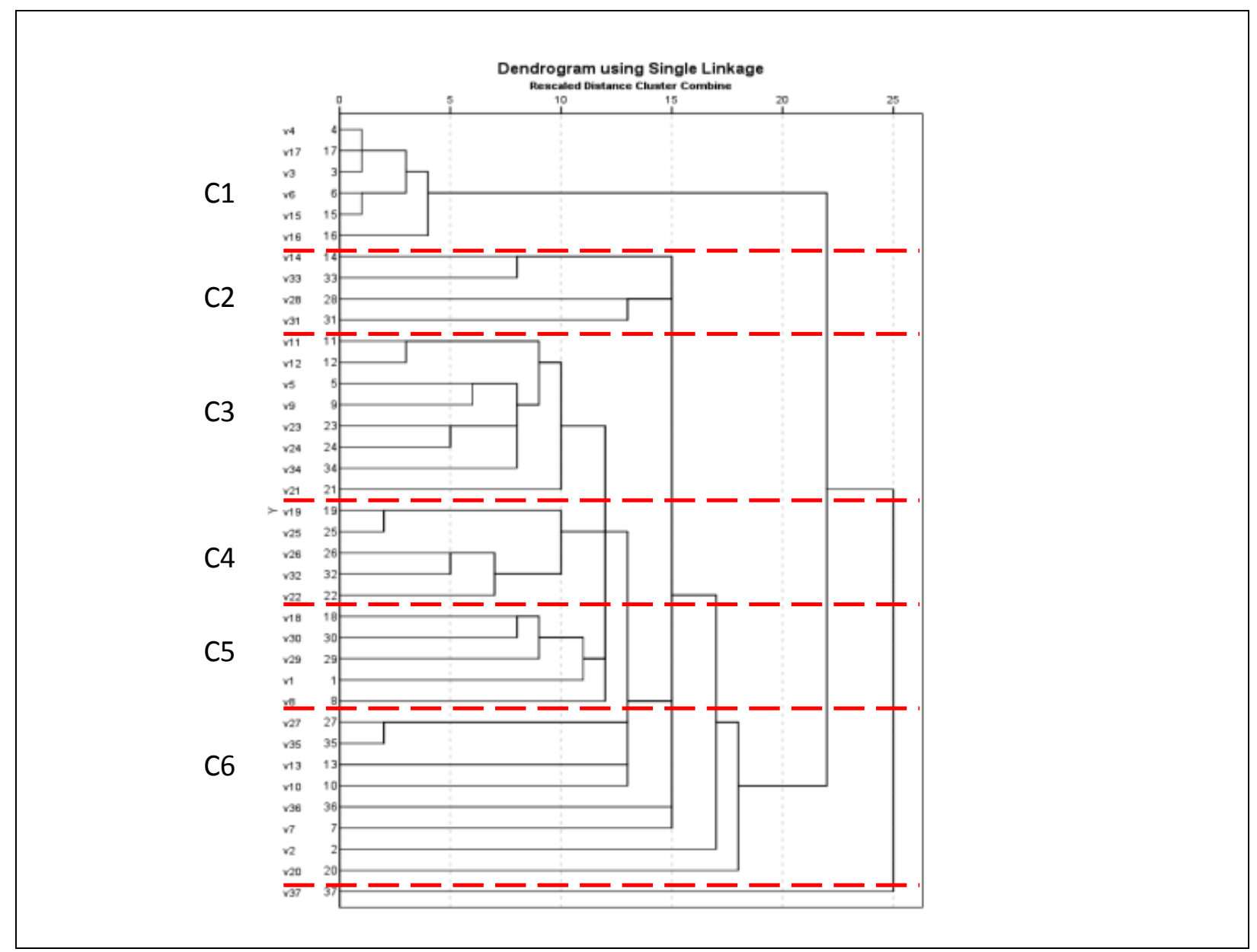

Figure 3: Teacher Candidate Clustering Dendrogram for Linkages

were combined into which clusters, with the elements, or variables, listed along the left side and the number of steps, or iterations, shown along the top. Figure 3 and Figure 4 present the dendrograms for the teacher candidates and teacher educators, respectively.

The dendrogram clusters (C1-C6) in Figure 3 are demarcated by the horizontal dashed lines. The reader may arguably perceive cluster demarcations that differ from ours. This interpretive variability is a normal situation for this type of analysis. That is, the lens of the analyst influences the interpretation of the results - just as much as the choice of the clustering option employed. The key to interpretation lies in the initial formation of small clusters, which when combined with successively larger ones, still make substantive sense in the shared commonality of the elements that have been combined. Reasonably different interpretations are possible at every step of this process. This variability is not surprising given our underlying assumptions about complex systems. That is, actors operating within a complex system, or observing as we as readers are presently doing, may have different but equally valid perceptions based on their positioning relative to the system (i.e. perspective), and this variability is part of what complex interpretations try to preserve (i.e. heterogeneity).

Our interpretation suggests that the teacher candidate and teacher educator groups differed in the number of clusters their elements formed: six and three, respectively. The candidates 


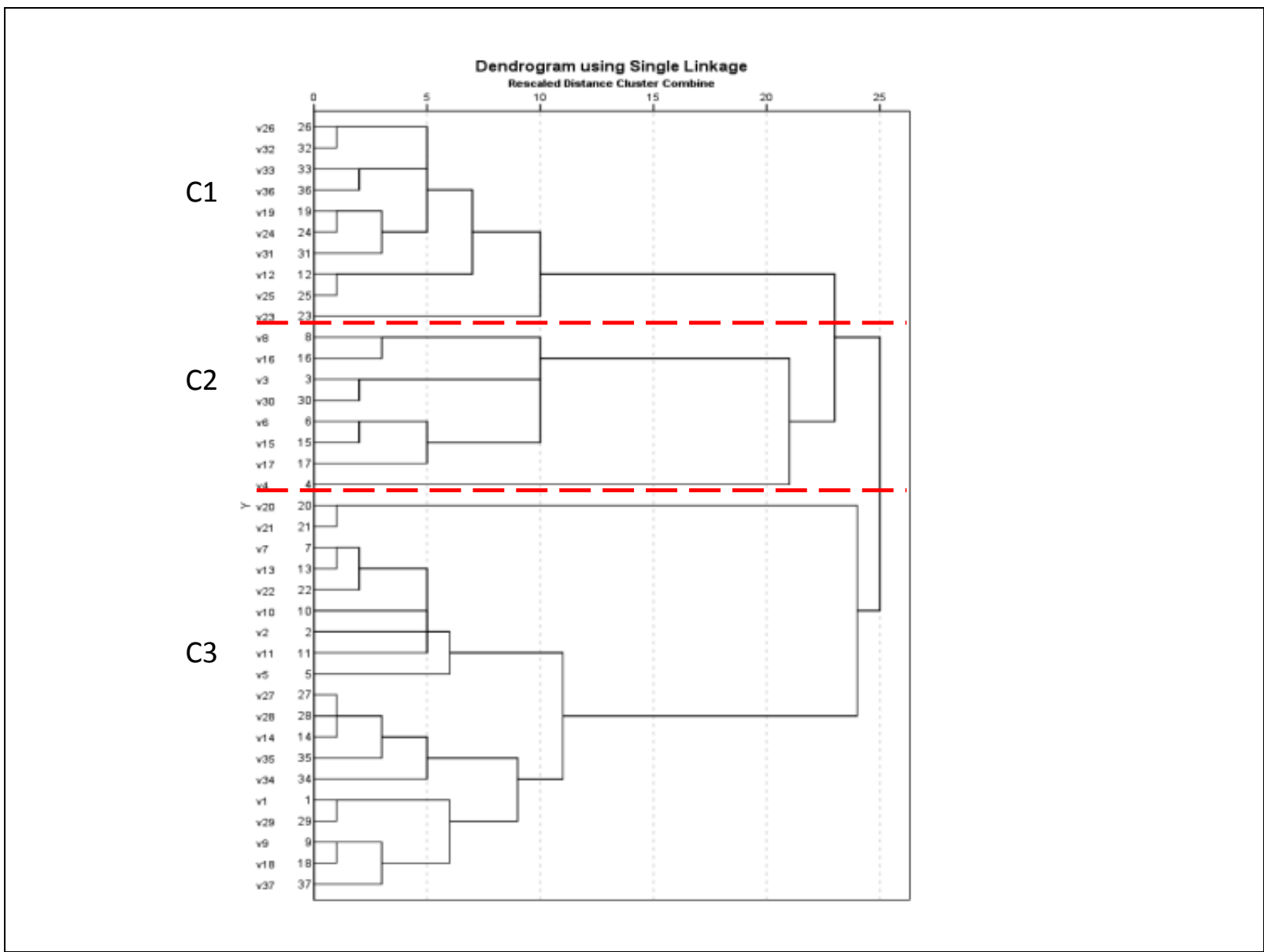

Figure 4: Teacher Educator Clustering Dendrogram for Linkages

perceived a large number of small clusters comprised of elements sharing narrow characteristics. The educators, in contrast, perceived the commonality existing among the same elements but clusters were more inclusive in their structure. In essence, the educators saw a broader pattern of interconnected elements than the narrower more discretely defined patterns of the candidates. For example, seven of the eight elements in cluster six (C6) for the candidates are located within the nineteen-element third cluster for the educators (C3).

It is important to remember that these clusters are based on the number of linkages drawn between element pairs but do not reflect participants' perceptions of the degree of influence these clusters of elements have on teacher candidates' learning. With the teacher candidate group, for example, some elements are tightly linked to one another (e.g., practicum administrators-V8, practicum office-V30, and teacher education program leaders-V18) and thus appear as part of a cluster (C6). As we know from Study 1, however, these elements were perceived by the teacher candidates as having little influence on their learning to teach. In contrast, other elements (e.g., personal beliefs and values-V15, prior knowledge-V16, and prior experience as a learner-V17) may be both tightly linked to one another as part of a cluster (C1), and, again from Study 1, also be perceived as having a strong influence on their learning.

The information gleaned from the element strength table and dendrogram clusters was subsequently combined in an effort to assess element strengths and linkages simultaneously. 


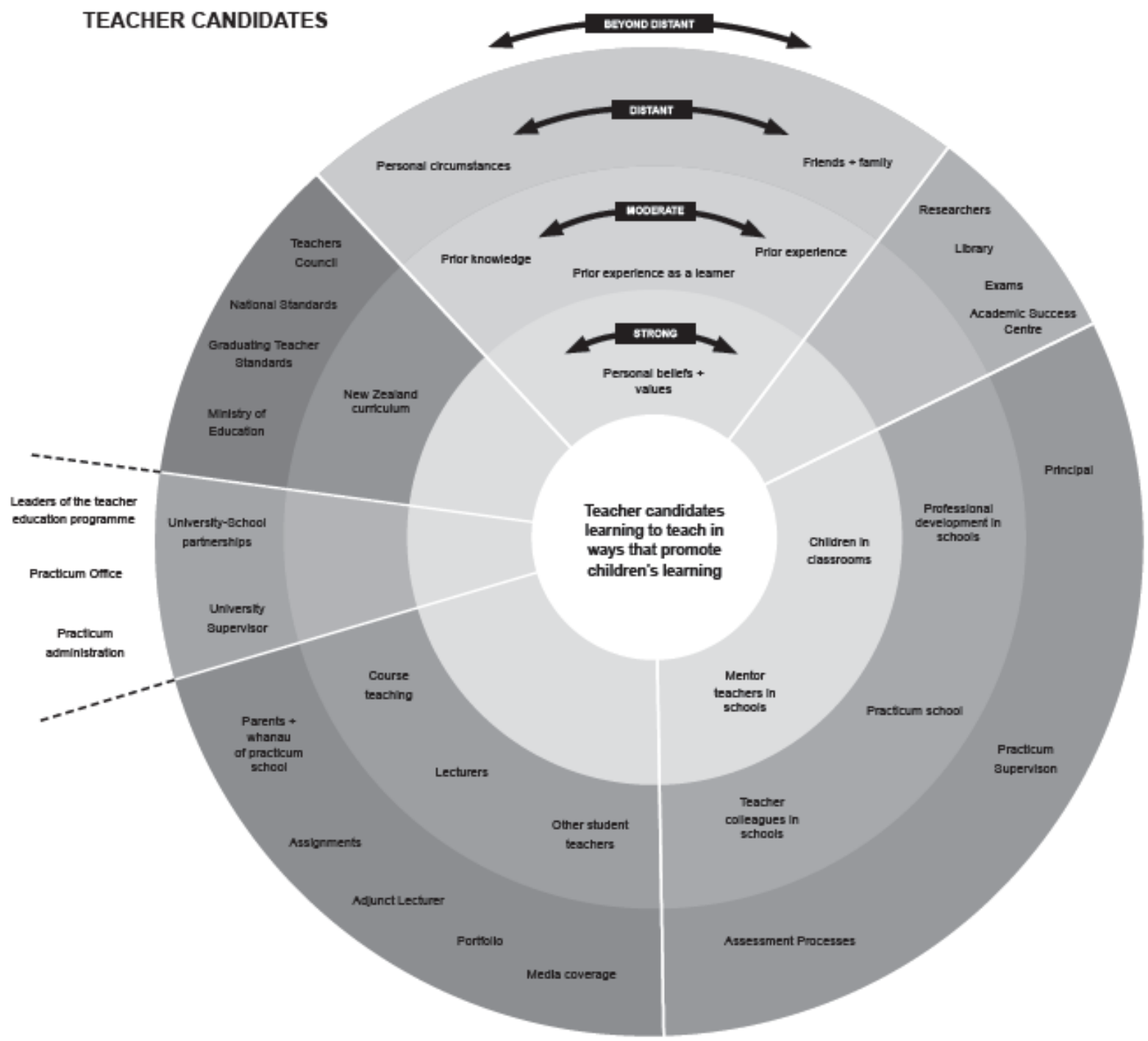

Figure 5: Teacher Candidate Strength and Clustering Pie Map

This strategy produced pie-chart diagrams of the teacher candidates' and teacher educators' perceptions of the nature of the ITE system. At the center of the diagrams (Figure 5 and Figure 6) is the key program goal: "teacher candidates learning to teach in ways that promote students' learning." Three concentric, shaded rings represent the average strength of influence assigned to each element by the respective stakeholder group. Elements with the strongest influence are in the darkest ring, closest to the center. Elements with weaker influence are further from the center with elements outside the circle having "beyond distant" influence.

The circles are divided into different sized wedges that represent both the strength of influence assigned to the elements and the dendrogram cluster within which the elements fell. This was done by employing a double-weighting scheme such that 8 was assigned to elements in a cluster with strong influences, 4 to elements with moderate influences, 2 to elements with distant influences, and elements with perceived influences beyond distant were assigned 1. 


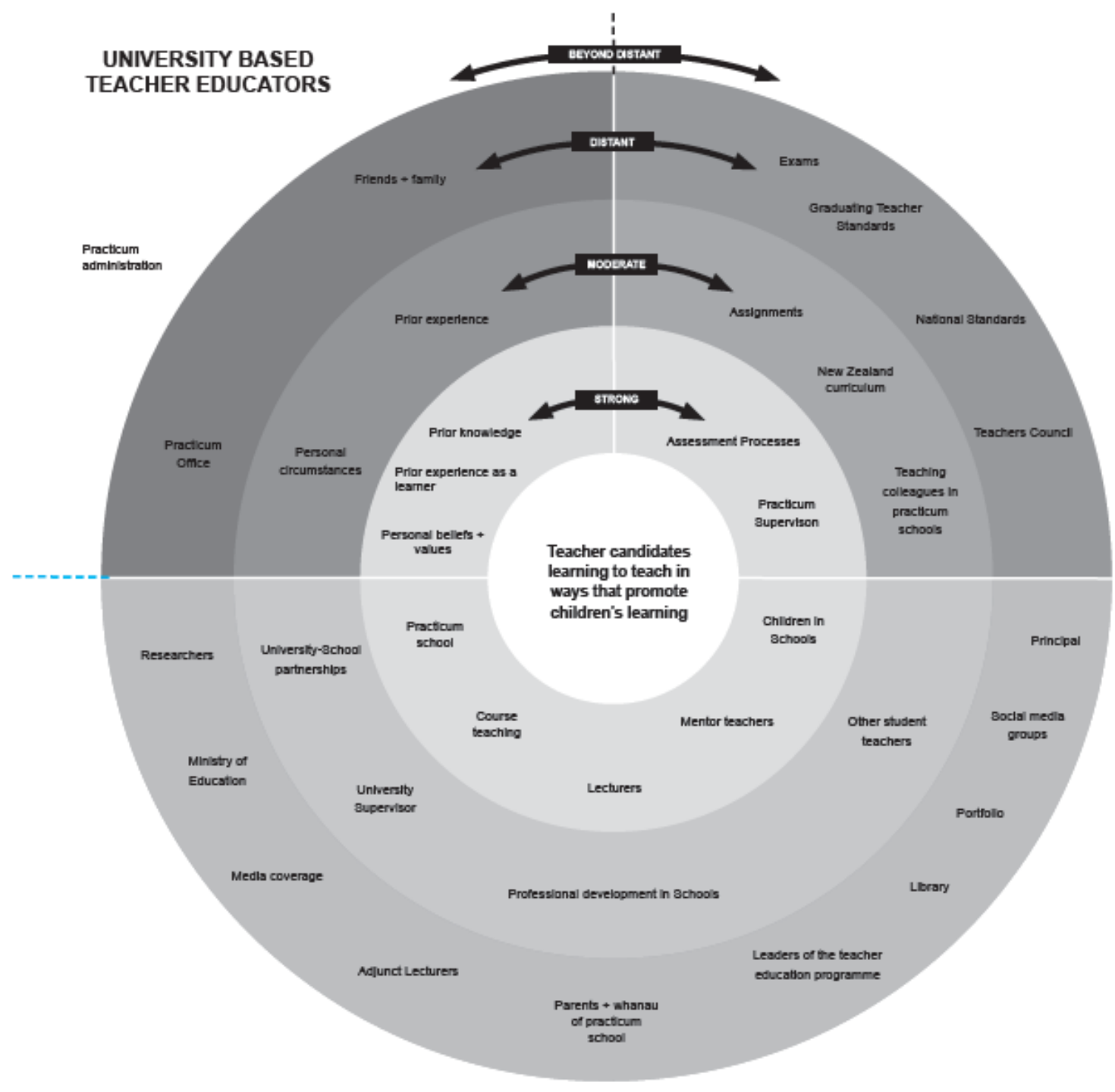

Figure 6: Teacher Educator Strength and Clustering Pie Map

These values were summed for each cluster and used to work out the percentage that each cluster contributed to the total of the weighted strength scores. This percentage was then used to calculate the degrees of the circle that should be assigned to that wedge (see Figure 5 and Figure 6). Although the weight values are arbitrary, any linear transformation of this weighting strategy will produce the same results.

For example, in Figure 5 the right-side wedge containing elements related to schools (C3 from Figure 3) is the largest because it contains elements that are ascribed relatively strong influence-two strong, three moderate and three distant influences. The left-adjacent cluster (C6 from Figure 3) also contains eight elements, but the cluster is shown as a smaller wedge because the elements are seen as less influential - three are moderate and five are distant influences. 
It is apparent from Figures 5 and 6 that the strongest influences (personal beliefs and values-V15, children in classrooms-V11, mentor teachers in schools-V5) are the same common elements identified by all four groups in Table 2 and they are all located in the innermost of the concentric rings in the diagram. In the next ring out from the center are moderately influential elements followed by distant and beyond distant elements. We now see that even though there were more clusters for the candidates in the Figure 3 and Figure 4 dendrogram comparisons, those clusters are generally comprised of elements with weak influence - as seen by more elements in the outermost rings in Figure 5 for the candidates when compared to the educators in Figure 6.

The pie-chart approach is useful for generating images of how the elements are related to one another and the extent to which the elements are perceived as having influence upon the teacher candidates' learning. The locations of the wedges within the pie-charts, however, are arbitrary. That is, the pie-charts could have been constructed with the wedges in different locations, so long as they maintained their same sizes. Hence, the wedges reveal nothing about how the clusters themselves are related to one another in their locations around the teacher candidates' learning as the focal point, nor do they adequately re-express at the group-level the individual graphical representations of the system as portrayed in Figures $2 \mathrm{a}$ and $2 \mathrm{~b}$.

\section{Study 3}

Study 1 and Study 2 addressed the question of strength of influence of the elements on the development of teacher candidates and how the elements tended to form clusters, respectively. The purpose of Study 3 was to investigate how the clusters were related to one another (a variation on RQ3). The data still consist of the linkage frequency counts but now the relevant question is: are there underlying characteristics or dimensions that unite or differentiate the clusters? Through multidimensional scaling, Study 3 sought a visual representation of how the individual maps might be combined to form "system consensus maps" capable of showing group-level patterns of inter-relationships among the elements.

The PROXIMITIES program took the aggregated group-level linkage counts and converted them to Euclidean distances among the elements - this meant that higher counts of linkages were represented as closer distances among elements and fewer linkages were represented as greater distances among elements. If an element was not used by a participant, the counts of links pertaining to that element were all coded as zero.

These distances were then subjected to the ALSCAL MDS procedure. The MDS "metric interval" option was selected (see Appendix [c]) since the data are quantitative but zero as a linkage value was not considered to be an indicator of absolute absence. The MDS geometric graphical output reveals detail about the underlying characteristics and commonalities which participants may have been thinking about when they formed their element linkages (Shepard, Romney \& Nerlove, 1972). To aid our interpretation we superimposed the cluster analysis results from Study 2 onto the MDS graphical image.

Figure 7 contains the MDS and cluster analysis results for the teacher candidates. A careful inspection of element locations in the figure reveals that their Cluster 1, which includes experiences, values and family, is to the left along Dimension 1. Cluster 3 is at the top of Dimension 2. The dendrogram pattern of Figure 3 suggests that clusters C4 (standard and 


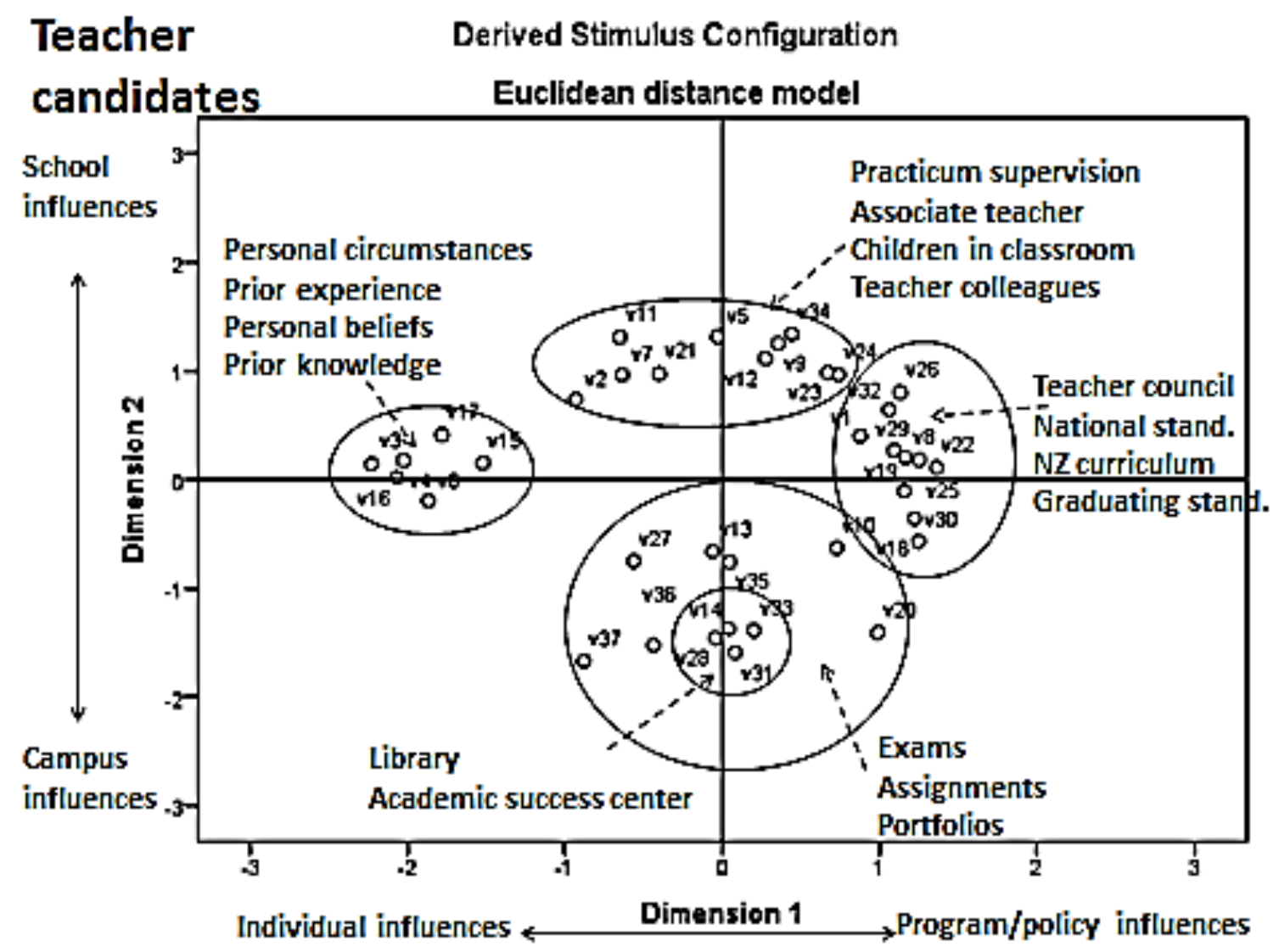

Figure 7: Teacher Candidate MDS and Cluster Solution for Linkages

regulations cluster) and C5 (distant people and structures) overlap. In Figure 7 those two clusters have merged (i.e. their boundaries intersect and overlap) and are to the right along Dimension 1. At the bottom of Dimension 2 is the mixture of elements that comprise the large cluster of $\mathrm{C} 6$ but it also includes the smaller cluster $\mathrm{C} 2$ nested within it.

From the left to the right we label Dimension 1 "individual-to-policy level influences" moving from personal on the left to structured professional development on the right. From the top to the bottom, Dimension 2 may be thought of as "school-to-university level influences" moving from classroom influences and persons to more formal and distant resources. The overall linkage pattern suggests a circular pattern of linkages across two broadly defined dimensions of influences.

It is important to point out that the rectangles framing "strength of influence" regions around the teacher candidates' learning box in Figure 1 and Figures $2 \mathrm{a}$ and $2 \mathrm{~b}$ are inappropriate to superimpose on these MDS results. This is because the counts of links between elements are independent of the teacher candidates' learning location. Statistically, the teacher candidates' learning element location in Figure 7 is indeterminate-all that we can interpret is the patterns of relationships the elements have with one another, we cannot interpret their strength of influence upon the teacher candidates' learning nor can we use these results as a graphic consensus map re-expression of what the individual maps look like in Figures $2 \mathrm{a}$ and $2 \mathrm{~b}$. 


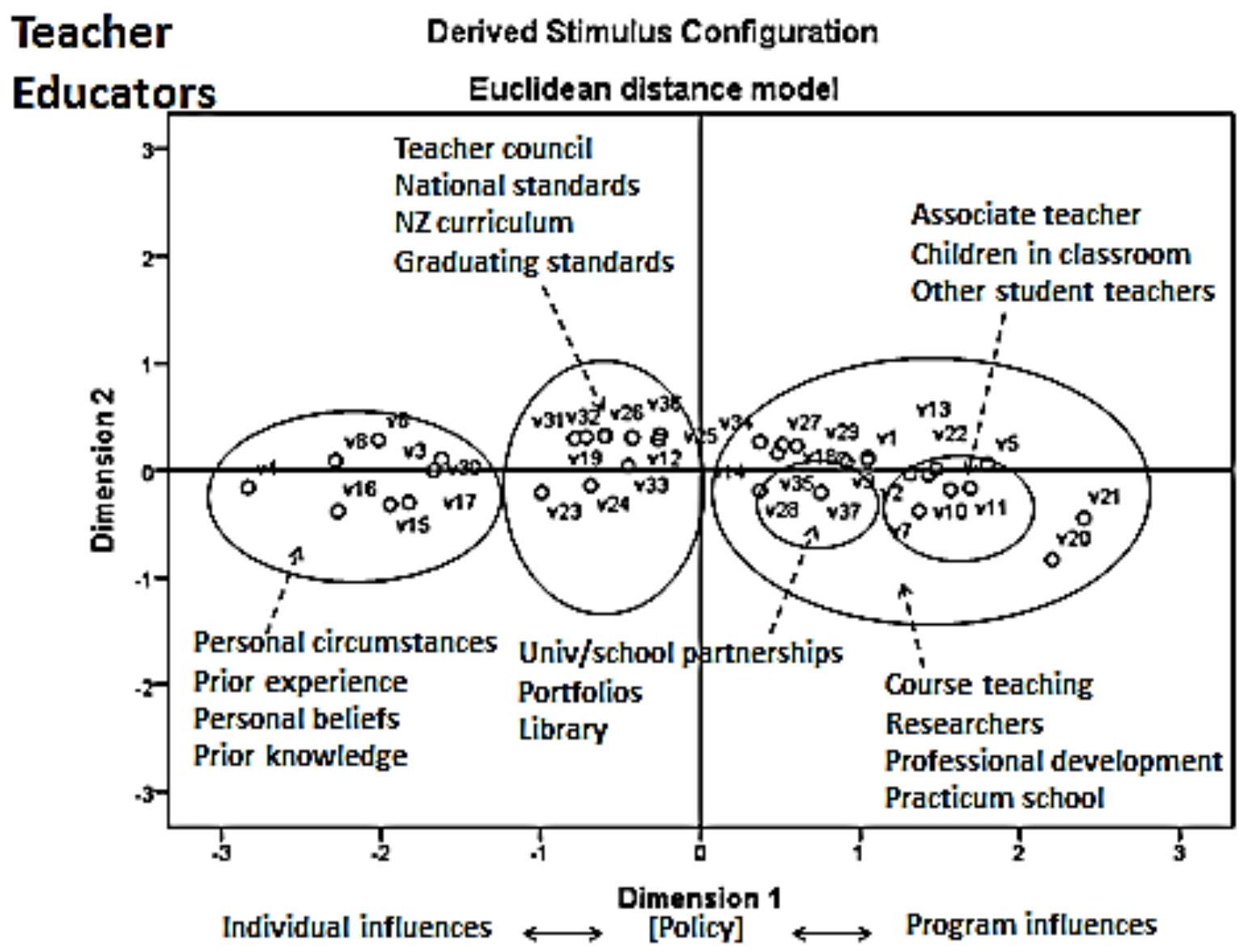

Figure 8: Teacher Educator MDS and Cluster Solution for Linkages

Figure 8 contains the MDS and cluster analysis results for the teacher educators. We immediately notice the much flatter shape - there clearly is not much of a vertical second dimension of separation here. To the left, cluster C2 consists of family, friends, beliefs, values, personal experiences. Cluster $\mathrm{C} 1$, in the middle, consists of the standards and assessments elements. To the right is cluster C3-a relatively large grouping comprised of influential people and professional development elements.

For the horizontal dimension we see that individual, personal influences on the left are linked to the policy elements in the center, and the policy elements are linked to the program elements on the right. This rather linear pattern of connections suggests that the teacher educators do not perceive strong direct links between the dispersed individual-level and program-level elements, rather, they see that through policy initiatives, standards, and requirements the individual is linked to what is required and accomplished through the program. We can again label Dimension 1 "individual-to-policy level influences." Dimension 2, however, is extremely weak in that it does little to further differentiate how the teacher educators perceived these sources of influence.

Overall, there is agreement by the teacher candidates (Figure 7) and the teacher educators (Figure 8) on the composition of the two primary clusters - individual influences, and policy influences. The primary difference between the candidates and educators, however, is how the 
candidates perceived a second clear dimension consisting of school-based and university-based elements-even though the previous results demonstrated that these particular sets of elements were perceived as weak in their influence on the candidates. The candidates perceive only a vague notion of how policies relate to individual, school and university-based elements - the educators, however, express policies as centrally influential in connecting these three sets of elements. In addition, the candidates perceive the elements as sets of common sources of influence but with relatively distinct and non-overlapping boundaries. The educators, in contrast, present a simplex system structure with clearly defined clusters which interact and overlap. In addition, Figure 8 for the educators is a reflection of years of experience which the candidates do not yet have. In essence, Figure 8 represents not just a perceptual difference between these two groups but a perceptual change from once being a teacher candidate to then growing into a teacher educator.

\section{Study 4}

Study 3 revealed patterns of relationships among clusters of linked elements perceived to have differing degrees of influence on teacher candidates learning to teach in ways that promote children's learning. Study 3 does not, however, show us how the elements specifically relate to the teacher candidates' learning as the central geometric focal point in the MDS linkage analysis nor does it show us what it would look like if we created a single "consensus" graphical representation of the original hand-constructed system maps presented in Figures $2 \mathrm{a}$ and $2 \mathrm{~b}$. The purpose of Study 4, therefore, was to take the element influence and linkage clustering results from Study 1 and Study 2 and the cluster-defined MDS dimensions from Study 3 and reexpress them as a graphical representation of the complex teacher education system relative to the teacher candidates' learning framed as the center of the mapping task (analogous to locating the teacher candidates' learning "element" at coordinates 0,0 in a two-dimensional plot) (RQ4). In essence, this set of MDS representations will serve as stakeholder-specific simplex system maps with the participants expressing their perceptions of influence as though they were located at the center of the system looking outwards in a $360^{\circ}$ sweep around them.

Unlike the linkage frequency counts used in the previous studies, the data for Study 4 consisted of the 38x38 distance matrices described earlier (where the teacher candidates' learning to teach is now included as one of the elements). The MDS "metric ratio" option was selected (see Appendix [d]) because now a value of zero indicates a true baseline of no difference in the distance between the locations of two elements. MDS was first performed on each of the original maps in order to ensure that the MDS statistical graphical representation of each of those maps was identical to each participant's original hand-constructed map. Figure 9, for example, is the exact MDS reproduction of the system map generated by person S6 presented in Figure $2 b$.

MDS stress and RSQ (R2) are two complementary indicators of statistical goodness-of-fit of the extent to which the generated MDS coordinates and corresponding inter-element distances reproduce the original distance data. A stress of 0 and $R S Q=1$ represent perfect fit between the original distance data and the reproduced distances based on the derived two-dimensional coordinates in the plot. Those values are only ever seen in perfectly simulated data. Since they 


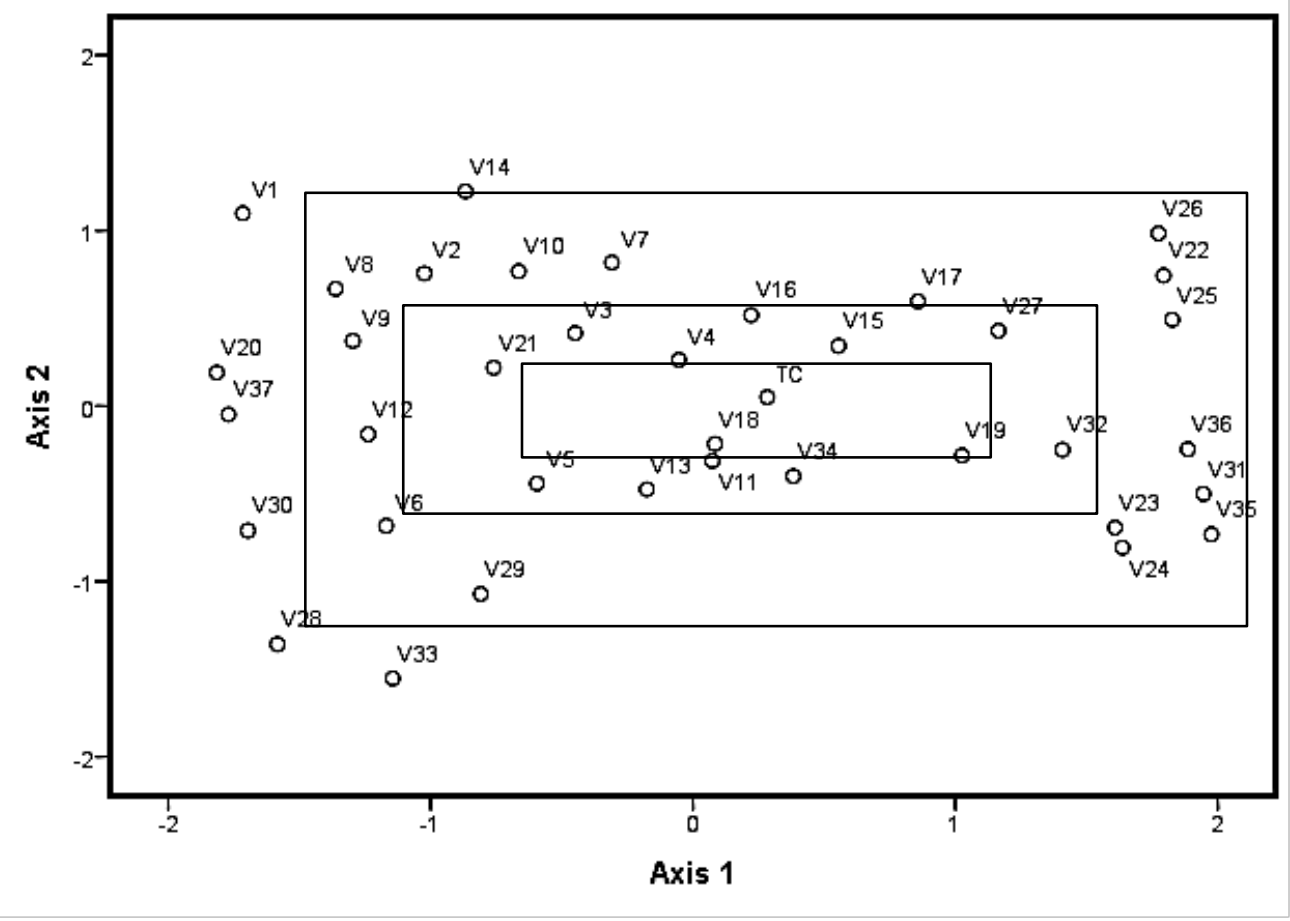

Stress $=.00319 ; \mathrm{RSQ}=.99995$

Figure 9: Multidimensional scaling recovery of person S6's map in Figure 2b

are not quite 0,1 for Figure 9, it simply means that our hand measurements of the $X, Y$ coordinates described earlier were slightly off for at least one pair of the 38 coordinates.

At this point we were concerned about the potential distortion that might result from elements that were not used by participants in their personal maps. Unlike the situation in the linkage analyses where an unused element contributed a zero to the counts of links between pairs of elements, here a "zero distance" would be inappropriate and incorrect. We therefore left the missing distances blank, and they were coded in the statistical software as "missing." A series of analyses were then performed to test the effect of missing data on the MDS results. Although the details are not presented here, the MDS performed on individual maps and on pairs of maps (one complete and one with missing elements) confirmed that the MDS procedures located the elements in coordinate positions informed by just the non-missing data. This is because the estimation algorithms use a pairwise estimation procedure that is robust to missing data (Shepard, Romney \& Nerlove, 1972).

Once each of the 76 original maps was replicated through MDS we ran group-level analyses and generated group-level "consensus" simplex system maps. These analyses employed an MDS model for analyzing individual differences (INDSCAL) (Takane, Young \& de Leeuw, 1977). INDSCAL takes the distance matrix for each individual in a group and creates a statistical solution that best represents the entire set of individual matrices, i.e., it generates a group-level map. This analysis is in contrast to analyzing a composite distance matrix generated 
from the average distances among elements computed across all the matrices. Such a composite matrix analysis would have obscured the heterogeneous variation inherent in the original individual maps - an important consideration to bear in mind for a complexity analysis and which will be illustrated below.

Because the original map creation task was relatively open-ended despite the strength-ofinfluence rectangular reference frames, participants within a given group placed the same elements in many different locations. We assumed, however, that element placements in the maps were not random with respect to similarity amongst elements and perceived level of influence on the teacher candidates. This means we expected some elements would tend to be consistently placed near one another but, unlike Study 1, elements located within the same rectangle would still reflect different distances from the teacher candidates' learning location. In other words, two elements within the same rectangle but with different measured distances from the teacher candidates' learning location would reflect a participant's distinction between the two elements and not simply reflect a random placement of them within the rectangle. Furthermore, we assumed the experiences, characteristics and perceptions that defined the individuals with the different groups would be reflected in different group-level consensus simplex system map representations of teacher candidates' learning.

Similar to Study 3, it was useful to employ cluster analysis to consider how elements grouped together under this direct form of MDS analysis of the inter-element distance data. Unlike Study 2 where the single-linkage clustering option was selected, the median method was selected as most useful because the single, complete, Ward and average distance clustering methods (IBM SPSS Statistics 22: CLUSTER) produced results that we considered distorted by individual elements placed extremely far away from the other elements. The median method, in contrast, is less influenced by outliers and is more stable, particularly for uneven numbers of elements within groups. Nevertheless, the cluster results we report are dependent on the approach we selected.

Statistically, outlier data only stand out as such against a background of stable norms or patterns. If outlier data influence the generation of the "consensus map" clusters and MDS coordinate patterns, their presence (and even their identification as outliers) may be obscured by the very patterns they have contributed to and the identification of outliers is not only an important diagnostic aspect of all statistical analyses but also for understanding the nature and structure of complex systems. Hence it is important to explore different options and procedures in order to see which ones work together to reveal a consistent pattern appropriate for interpretation.

While MDS has traditionally been interpreted in the context of dimensions (e.g., the vertical and horizontal axes that the MDS plots possess), Study 4 necessitated a somewhat different interpretation due to the centrality and focus on the teacher candidates' learning location in the original mapping task. In traditional MDS analyses, it is often desirable to interpret underlying dimensions of proximity as moving from less to more of a particular quality depending on the nature of each mapped variable. Now, however, the teacher candidates' learning (TC) location is the central reference point in the mapping activity (Note: there was no such central fixed reference point in the prior MDS linkage analyses), and because mapping element proximity to the teacher candidates' learning location serves as the purpose of the present task, axis 
dimensionality alone provides an incomplete, if not inappropriate, interpretation of element relationships (Shepard, Romney \& Nerlove, 1972; Young, 1987).

Since MDS literally provides a geometric "picture" of the location of each element in terms of both its level of influence on the teacher candidates' learning (through the "strength" rectangles) and the element's relationship to the other elements (through the clusters), we focus on the patterns of closeness of clusters to the teacher candidates' learning location and to one another. This perspective means the MDS and clustering results from the earlier linkage data analyses are not expected to be the same as the current distance data results, (e.g., two elements with few links between them may still lie close together in a participant's original map). Hence we focused on how the results differed and what new insights we could gain through this distance analysis and fixed central reference point method.

Interpretation of the teacher candidate MDS consensus map

The consensus MDS simplex system map for the teacher candidates reflects how they, as a group, perceived the influence of the system elements on their learning to teach in ways that promote children's learning. Their MDS two-dimensional graphical representation with clusters containing the elements is presented in Figure 10.

Figure 10 shows not only how the elements are clustered (Study 2) and how the clusters relate to one another (Study 3), but also the degrees of influence (Study 1), represented by the rectangles, that the participants used to orient their original placements around the central location of the teacher candidates' learning. Similar to Figure 7 we see a circular pattern in the arrangement of the clusters. Unlike Figure 7, however, we now see five, not six, clusters. This difference is a reflection of the form of data. Here we are analyzing the physical distances among the element locations as the participants had placed them on the maps. Study 2, captured in Figure 7, was based on the number of drawn linkages among the elements - there is no statistical reason to expect the results to be the same. Neither approach is necessarily better or "more correct" - they simply reflect different exploratory ways of trying to understand how participants understood the ITE system.

The critical difference here in Study 4 using distances and Study 2 using linkages lies in the observation that in contrast to Figure 7, Figure 10 expresses the teacher candidates' perceptions of the ITE system from the central position of elements located around teacher candidates' learning. This means that our interpretation of what their thinking might have been that led to their element placements in the original construction of their maps depends upon the geometric location and direction from which the simplex system represented in their Figure 10 is viewed.

For example, the orientation of a viewer looking at Figure 10 is from an imaginary perpendicular axis rising toward the viewer. In essence, we are looking down at a flat twodimensional surface. This orientation shows clusters and elements moving from the left to the right and from top to bottom. Our interpretation of element relationships shifts if we hold the page flat in front of our eyes and all we see is a single, thin dimension moving from left to right. If we physically turn the page 900 so that we are looking at the system map from the right hand side of Figure 10, we will see different relationships and patterns even though the actual coordinate locations of the elements do not change. We can even imagine standing on the central teacher candidates' learning location (TC is located at 0,0 in the center of the 


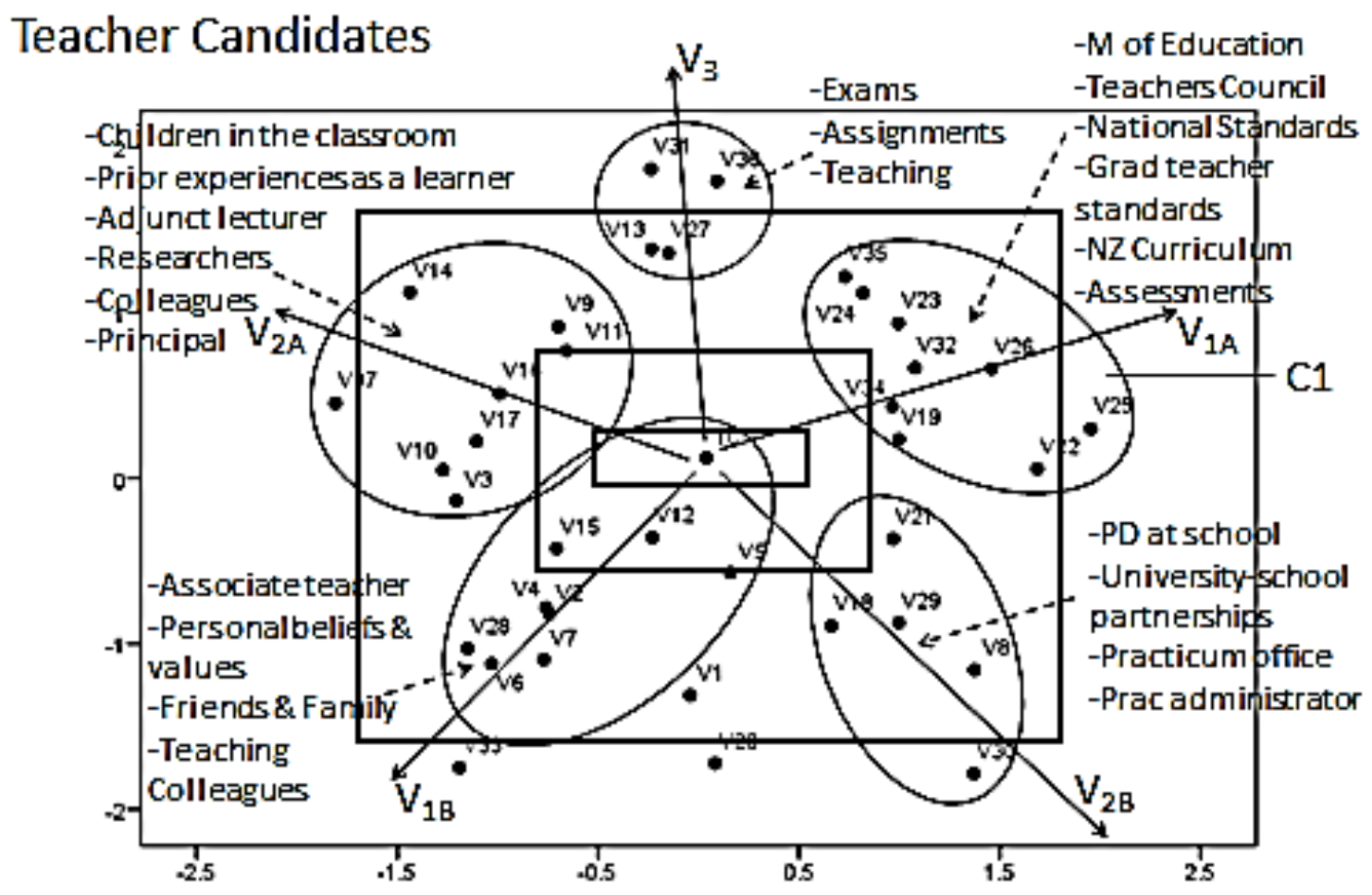

Figure 10: Two-dimensional Teacher Candidate MDS and Cluster Solution for Distances

strongest-influence rectangle) and looking outward at the elements surrounding us. The point of this orientation discussion is that it may be that most stakeholders agree on the inclusion of most of the elements but where they personally "stand" relative to, and within, a complex system reflects their perception of which elements are more or less clustered and influential on teacher candidates learning to teach. We offer this suggestion as a powerful illustration of the complexity notion of "perspective."

The closest element to the teacher candidates' learning location (TC) is "teaching colleagues at practicum school" (V12). Although the dendrogram showing the clustering steps is not presented for space reasons, TC and V12 formed the first clustering step followed by the other three strong influences reported in Table--V5 (mentor teachers), V11 (children in classrooms) and V15 (personal beliefs and values). The interesting observation here is the surprising appearance of V12 as a strongly influential element. In the present analysis the average distance of V12 to TC was closer than any other element even though its average influence rating was less than 2.5 (from Study 1). This apparent discrepancy occurred because of two teacher candidates who placed their "teaching colleagues at practicum school" sticky notes in the "distant" sections of their maps. Their two outlier locations subsequently skewed the average calculation of influence in Study 1 more drastically than the average distance calculations here in Study 4.

When those two candidates are removed from these analyses, V12 shows up in Table 2 as one of the most influential elements for the candidates and Table 2 becomes consistent with 
Figure 10. We did not, however, actually remove those candidates from the analyses reported in this paper. They are left in as examples of differing personal perspectives, heterogeneity in responses, and statistical results that are a function of participant characteristics, statistical options, and the interpretive lens of the analyst.

Since the interpretation of the element relationships to one another and the teacher candidates' learning depends on the orientation of the viewer with respect to one's location in the space, imagine yourself at the teacher candidates' learning location in the middle of the plot. From this location it is possible to envision many vectors of orientation projecting outward from your location through the two-dimensional swarm of points around you, in essence, a form of virtual reality in the midst of a swarm of geometrically located data points. Five such handconstructed vectors have been labelled V1A, V1B, V2A, V2B and V3. No statistical assumptions of independence or orthogonality have been placed on the construction and orientation of these vectors. They simply represent alternative ways of looking at the elements if one were standing at the teacher candidates' learning location and looking outwards through the elements' geometric space from that spot. This form of axis definition is the qualitative version of the early factor analytic rotation procedure of oblique Procrustes rotation wherein the analyst determines the axis orientation to fit to the data (Browne, 1967).

From the teacher candidates' learning location at the center of the plot and projecting outward along V1A through the upper right quadrant are elements all associated with various initial teacher education governing body regulatory standards. Projecting along V1B through the lower left quadrant are teacher candidates' personal experiences and relationships with friends, advisors and family. V1A and V1B are consistent with the interpretation of Dimension 1 in Study 3 for the teacher candidates: "individual-to-policy level influences". The difference is that teacher candidates' learning is now perceived as being squarely in the middle of the simplex system of influences.

Likewise, if we position ourselves at the teacher candidates' learning location and look out along V2A through the upper left quadrant we see teaching experiences that are personal and classroom-based and then along V2B through the lower right quadrant we see elements that are more formal and structured in their influence on teacher candidate preparation. V2A and V2B are consistent with Dimension 2 in Study 3 for the teacher candidates: "school-to-university level influences".

At the center of the space, then, is the teacher candidates' learning with elements that tend to be more personal and experience-based and then projecting further out into the ITE simplex system space we see influences that are less personal and more formal and regulatory. To a certain extent, the vector projection (V3) out to the cluster consisting of exams and assignments suggests these elements are modest, even irrelevant, influences in the perception of the teacher candidates.

Interpretation of the teacher educator MDS consensus map: The teacher educators' MDS twodimensional simplex system graphical representation with clusters containing the elements is presented in Figure 11. The same form of distance data and MDS analysis and clustering options were employed. 


\section{Teacher Educators}

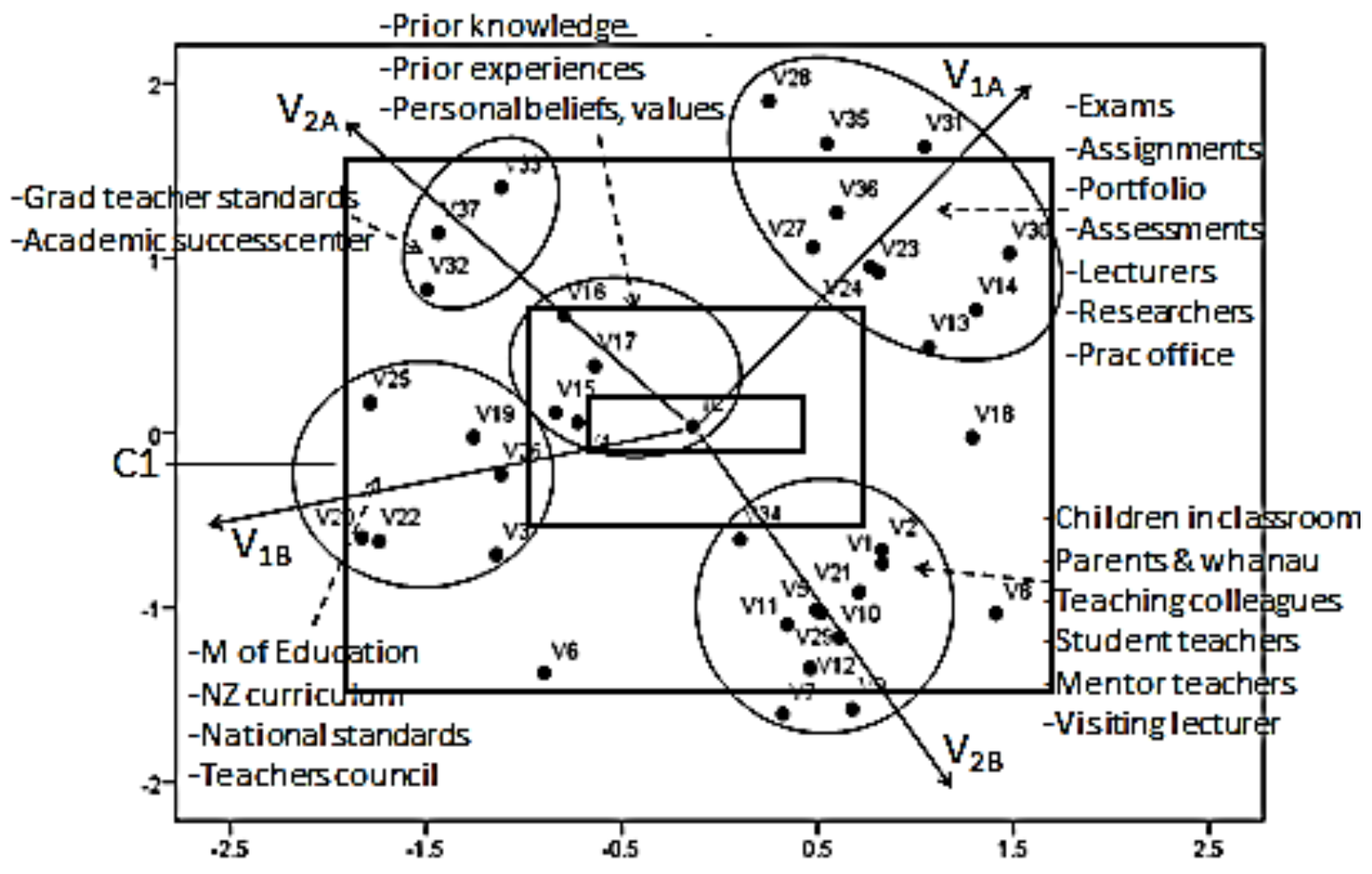

Figure 11: Two-dimensional Teacher Educator MDS and Cluster Solution for Distances

Comparing Figure 10 and Figure 11 we find there is a clear perception amongst the educators that teacher candidates must recognize and address coursework and professional standards in their preparation. The educators see V1A projecting from the teacher candidates' learning location through the upper right quadrant to coursework assignments and experiences. V1B projects through the lower left quadrant capturing the formal requirements of curriculum and national standards. The vector projecting through the upper left quadrant (V2A) captures another small set of formal standards and assessment while V2B projecting through the lower right quadrant captures personal relationships with family, friends, and colleagues.

From the perspective of teacher educators, however, the strongest influences upon the teacher candidates' learning were the teacher candidate's beliefs, values and prior experiences - the tight cluster in the center of the plot that V1A, V1B, V2A and V2B originate from. Even though the teacher candidates may perceive their classroom experiences and relationships with professionals as critical (as represented in Figure 10), the teacher educators perceived all of those influences as filtered through the teacher candidates' personal beliefs and experiences. With their years of experiences as teachers, mentors, supervisors and university academics, the teacher educators perceive early experiences and personal characteristics of teacher candidates as much more influential than is appreciated by the candidates themselvesin essence, the influences of early conditions of personal characteristics only become apparent, or emerge, over the long-term course of one's career. 
For the teacher educators, this orientation at the center of the consensus system map and vector representation of the influences upon the teacher candidates' learning is much richer than the relatively linear and one-dimensional representation presented in Figure 8 using the linkage data. In fact, we can clearly see how the linkage and distance data extracted from the same mapping exercise address two very different questions: how do the elements relate to one another versus how do the elements relate to the teacher candidates' learning, respectively? Unlike the relative similarity in the two-dimensional linkage and distance MDS spaces perceived by the teacher candidates in Figure 7 and Figure 10, the only similarity in the teacher educator's Figure 8 and Figure 11 linkage and distance MDS spaces is in the composition of the clusters.

These differences in the results mean that how those clusters suggest degrees of influences upon the teacher candidates' learning depends on the form of the question (e.g., what are the element relationships relative to-each other or an external reference such as teacher candidates' learning?), the type of data (e.g., frequency counts of element linkages or metric distances among element locations?) and who is asked (e.g. teacher candidates or teacher educators). The subsequent analyses and interpretations may be complementary in their representation of a complex system but they will be different-highlighting the point that an understanding and representation of any given system requires an interwoven series of approaches and perspectives.

\section{Study 5}

When teacher candidates' learning is included as the focal point element in the MDS system analysis, it is possible to conceive of individual differences in participant perceptions of system elements as individual vectors projecting outward from the teacher candidates' learning location. Intra-group differences may be less than inter-group differences but no two participants should be expected to perceive the system - whether defined as the overarching complex system or the narrower group-specific simplex system - in the same way. This means every participant's map may be understood as a unique vector orientation of how an individual experienced the system while at the same time it is understood that there is a relatively commonly-perceived initial teacher education ITE system comprised of common elements that differ in their perceived relationships and strengths and boundaries of influence.

The important point about individual differences is that it is unlikely that the relationships among the system elements and their influence upon the teacher candidates' learning can be adequately represented in just the two dimensional (2-D) representations in the preceding figures. This is because common elements even within a relatively clearly defined group such as teacher candidates will inevitably be experienced and perceived differently. Hence, the purpose of Study 5 is to investigate what we can learn from three-dimensional (3-D) representations of the ITE distance data (RQ5).

Figure 12 is the 3-D plot of the teacher candidate perceptions of the ITE system, and Figure 13 is the teacher educator's corresponding plot. The elements within each cluster are given a common color according to how the elements clustered in Figure 10 and Figure 11, respectively. For example, the dark blue-colored elements within the oval labeled C1 in Figure 12 correspond to the $\mathrm{C} 1$ cluster of elements in Figure 10. Also note the location of the teacher candidates' 


\section{Teacher Candidates 3-D Scatterplot}

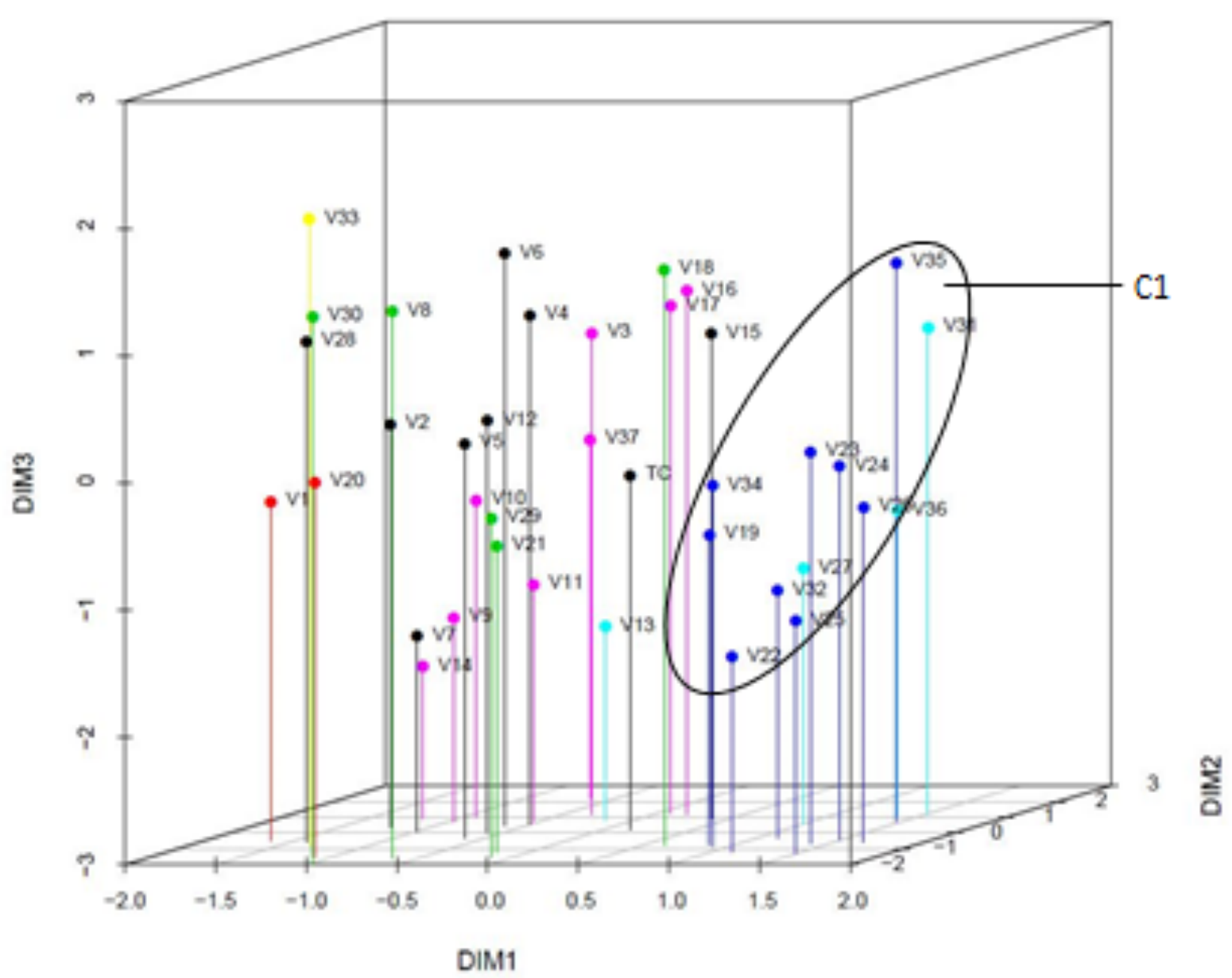

Figure 12. Three-dimensional MDS plot for the teacher candidates.

learning (TC) element in the center of both figures (coordinate position 0,0,0) - unlike the flat 2D surface representations in Figure 10 and Figure 11, here we see the elements clearly swirling around the TC in the midst of a multidimensional simplex system.

A useful way to think of a 3-D plot is as an ordinary six-sided box. Although the relationships among the elements within the box remain fixed regardless of how the box is turned and looked at (e.g., the TC element remains at coordinate position $0,0,0$ ), what the viewer of the box sees and interprets as element relationships and cluster boundaries depends on the direction from which the box is viewed. For example, if the viewer's perspective is from the top of the box looking downwards, the relationships among the elements are captured by the 2-D plots of Figure 10 and Figure 11. So if there were no need for a third dimension the plots as presented in Figure 12 and Figure 13 would simply look like a relatively flat scatter of points moving from left to right across the mid-level of the two figures. That is, there would be no vertical third dimension. 


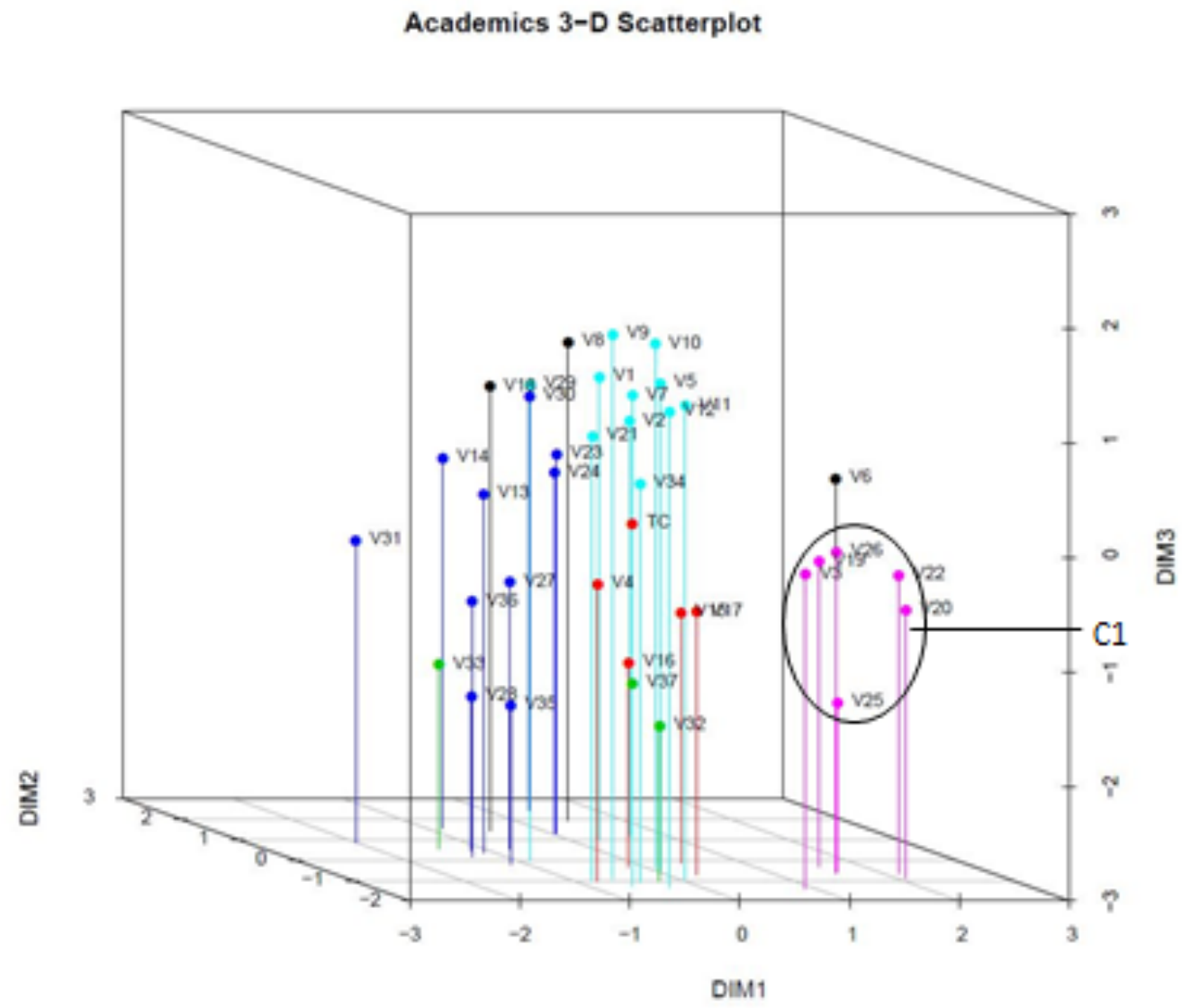

Figure 13. Three-dimensional MDS plot for the teacher educators.

The orientation of the 3-D spaces as presented to the viewer in these two plots is arbitrary in the sense that the statistical software provides a 3-D plot that may be rotated around any of the three axes. This means the 3-D orientation presented here was selected by us to maximize the opportunity to more clearly see heterogeneity within the element clusters presented in the 2D plots in Figure 10 for the teacher candidates and Figure 11 for the teacher educators.

Recognizing that different rotations of the 3-D space will present different perspectives about how these elements and clusters lie within these 3-D boxes, it is still clear that incorporating a third dimension provides additional information about element and cluster relationships. That is, not all elements within the same cluster represent a single common characteristic - as is suggested by the 2-D plots in Figure 10 and Figure 11.

Take for example the cluster denoted C1 in Figure 10 and Figure 12 for the teacher candidates. This cluster consists primarily of elements addressing various forms of assessment and regulatory standards. When looking at Figure 10, it is as though we are looking down at the 3-D box and cluster C1, with no appreciation of a third dimensional space lying either beneath or above the flat 2-D surface. Looking at Figure 12, however, we see the elements in C1 spread out on the third dimension (DIM3) in a meaningful way - those elements separate out into "national-level" standards and regulations in the negative direction of the third dimension versus "local-level" standards and assessments in the positive direction. Here the Ministry of 
Education (V22) in the lower level is the epitome of national regulations while the Portfolio element (V35) in the upper level constitutes an obvious personal form of assessment.

The same type of differentiation among elements may be seen when we compare the clusters represented in Figure 11 and Figure 13 for the teacher educators. In cluster C1 in Figure 11 the elements represent different sources of influence from regulatory standards and governance bodies - similar to but different from the teacher candidates' C1 clustering. In Figure 13 those elements, again, separate out into national-level influences versus local-level influences - here the Teacher Council (V25) in the lower level of the oval is distinguished from the other elements.

The 3-D plots, more so than the 2-D plots, provide a realistic sense of systems comprised of elements that are clustered based on proximity and common features, clusters that form permeable boundaries of influence, and systems with structures that are stakeholder-dependent and capable of shifting over time. It is not difficult to imagine standing in the middle of these 3D plots and looking around to take stock of the forces shaping one's development and career. In addition, the 3-D plots statistically fit the data better than the 2-D plots for both the candidates and educators, i.e. stress dropped and RSQ increased.

Given this image of being at the center of the system, it seems reasonable to ask: where are the individual participants located in these two simplex system representations? That is, if all participants perceived the elements and their relationships in the same way when they first constructed their maps, then their own personal locations in their respective simplex system geometric representations would be at the center of the system, i.e. at location $0,0,0$. Since this is unlikely given the variation we have seen so far, which clusters and orientations within the system did individuals align themselves with? In other words, how are individual differences represented in this form of system analysis?

\section{Individual differences}

Similar to Figure 10 and Figure 11 where the orientation of interpretation was from the center of the system looking outward, it is possible to imagine vectors of influence projecting from the 3D origins out through the clusters of elements in Figure 12 and Figure 13. Such Procrustes-like vectors would represent the consensus of the group about how strong an influence different clusters have on teacher candidates' learning (by the proximity of the cluster to the origin) and how interrelated the elements are (by the compactness of the clusters). Those projections could be illustrated here, as they were for their respective 2-D counterparts in Figure 10 and Figure 11, but we introduce instead an alternative way to locate each participant within their respective simplex system representation.

The individual perceptions of the element influences and relationships defining the simplex structure for the teacher candidates are captured in Figure 14. In Figure 14 we have the 3-D "subject weight" coordinate locations of the 23 teacher candidates in terms of how their individual original maps emphasized, or weighted, the three dimensions in their Figure 12 3-D simplex system plot (Takane et. al., 1977). Each point in the plot (the terminal point of a vector originating at location $0,0,0$ ) represents a teacher candidate and the arrangements of these locations in the plot reveal, not surprisingly, that candidates expressed different weighted 


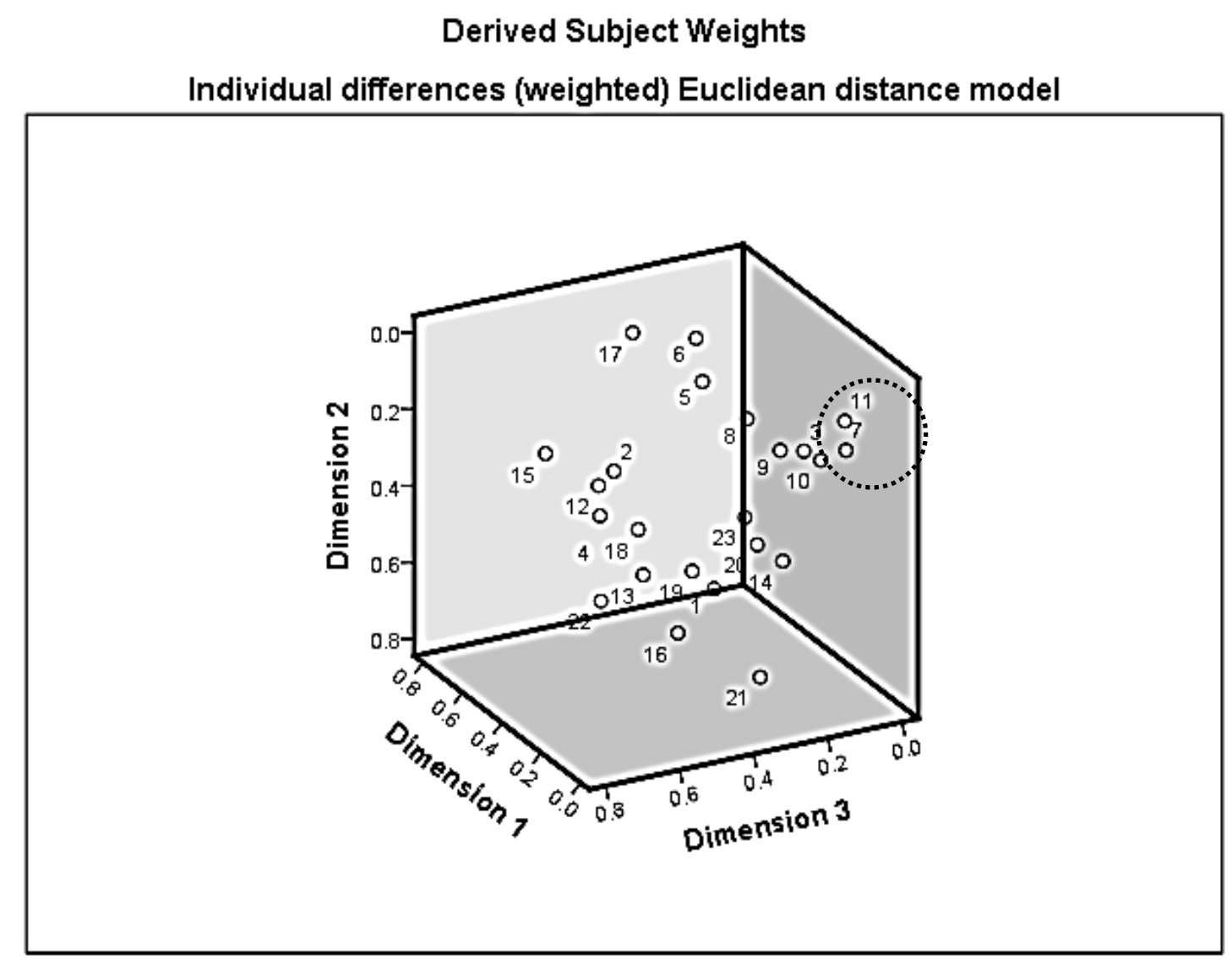

Figure 14. Three dimensional plot of teacher candidate MDS weights

perceptions of the clusters of influences captured in the vector projections presented in Figure 12.

Unlike Figure 12, however, where the orientation of the three dimensions was rotated to best show the relationships among the element clusters, Figure 14 has been rotated to highlight one of the mapping data and complexity theory characteristics alluded to earlier. That is, even within a group, such as teacher candidates, whose members have in common their participation in the same teacher preparation program, there is diversity in perceptions of element influences and inter-relationships. More specifically, the rotation orientation of Figure 14 shows a small cluster of teacher candidates in the right-hand plane of the plot. Focusing upon teacher candidates \#3, 7, 10 and 11, their spatial coordinates correspond roughly to weights of $(0,0,0)$ in the three dimensions (e.g., the weights for $\# 11$ were $.09, .09, .07)$. Since this subject weight plot shows how participants tended to perceive or weight each of the three dimensions, the coordinate locations for these four teacher candidates represent maps which were considerably different from the other 19 teacher candidates. That is, they essentially gave zero weight to the three dimensions their peers used to construct their maps.

In fact, their maps are so different from the other maps in their group that the 2-D and 3-D MDS solutions presented in Figure 10 and Figure 12 are somewhat distorted by the inclusion of their four maps-similar to the earlier discussion about outliers influencing the clustering results. This distortion can be seen in Table 3 which contains the MDS stress and RSQ indicators 
of statistical goodness-of-fit. For these four teacher candidates (indicated by an "**" using a "badness-of-fit" selection criterion of stress $>.45$ and RSQ $<.10$ ) it is apparent that their individual maps exhibit high stress and low RSQ when the MDS analysis includes their maps in the generation of the overall group solution.

For example, compared to the group simplex system map in Figure 10, teacher candidate S11's map (not shown) reveals that: a) exams (V31) and assignments (V36) were placed on opposite sides of their map unlike the tight cluster arrangement at the top of vector V3 in Figure $10, \mathrm{~b}$ ) associate teacher (V5), principal (V9), professional development in school (V21), practicum supervision (V23), practicum school (V34) and portfolio (V35) are all placed in the "strong" influence section near one another and close to the TC central position unlike their dispersed placement in three different directions in the "moderate" section of Figure 10, and c) national curriculum (V19), national standards (V26) and graduating teacher standards (V32) are placed close together in the "strong" influence section of S11's map unlike their placement in the "moderate" influence section along vector V1A in Figure 10.

\begin{tabular}{|c|c|c|}
\hline Candidate & Stress & RSQ \\
\hline 1 & 0.302 & 0.465 \\
\hline 2 & 0.287 & 0.506 \\
\hline $3^{*}$ & 0.456 & 0.089 \\
\hline 4 & 0.277 & 0.576 \\
\hline 5 & 0.333 & 0.427 \\
\hline 6 & 0.262 & 0.674 \\
\hline $7^{*}$ & 0.513 & 0.045 \\
\hline 8 & 0.412 & 0.183 \\
\hline 9 & 0.459 & 0.126 \\
\hline $10^{*}$ & 0.462 & 0.086 \\
\hline $11^{*}$ & 0.499 & 0.025 \\
\hline 12 & 0.299 & 0.565 \\
\hline 13 & 0.166 & 0.788 \\
\hline 14 & 0.357 & 0.337 \\
\hline 15 & 0.161 & 0.816 \\
\hline 16 & 0.199 & 0.720 \\
\hline 17 & 0.225 & 0.722 \\
\hline 18 & 0.212 & 0.675 \\
\hline 19 & 0.231 & 0.643 \\
\hline 20 & 0.327 & 0.375 \\
\hline 21 & 0.209 & 0.729 \\
\hline 22 & 0.221 & 0.742 \\
\hline 23 & 0.363 & 0.294 \\
\hline
\end{tabular}

Table 3. Example of heterogeneity within the teacher candidates' maps 
This discovery of extreme individual differences and heterogeneity of perceptions and experiences within groups is significant for multiple reasons (since similar extreme variation was found in the teacher educator maps, there is no purpose served in presenting them here). It suggests that the "best-fitting" teacher candidate ITE system map would be one without these four particular maps included - a process that could be repeated until the best-fitting statistical criterion produced a solution for only a subset of the full data. Although this best-fitting iterative procedure is common for traditional variance-partitioning procedures (e.g., ordinary least squares regression) where $5 \%$ of the data may be trimmed to yield stable parameter estimates, such an action would be contrary to the spirit of a complexity analysis where heterogeneity is expected. Maintaining their four maps in the generation of the group solution highlights the opportunity that this methodology presents for uncovering outliers - and then trying to understand them. Finally, even within a group of people like teacher candidates who have some common experiences and interests, given their participation in the initial teacher education program, there is no one definition and perception of the nature and structure of the ITE system. This suggests that there is no single fixed ITE system space but instead a set of fluid and changing simplex system spaces each of which is dependent upon the system observer or participant. The representation of a group consensus simplex system map is then a construction from mutually agreed upon elements, each of which is perceived to exert different degrees of influence upon teacher candidates' learning while the perceived relationships among these elements are a function of not only system structures such as governing regulations and standards but also the idiosyncratic personal circumstances of each stakeholder.

The final concept we wish to illustrate is that these stakeholder-specific simplex system maps are nested within the broader complex system of initial teacher education as perceived by all participants in our investigation. This means we can ask: What does the ITE complex system look like for everyone considered simultaneously? Figure 15 contains the 2-D system map representation for all participants. Similar to previous plots, an interpretation can be provided for the element clusters and levels of influence upon the teacher candidates' learning. But the point here is that this representation is an aggregation across all participants and, as such, does not represent the perspective of any single group or person.

The clusters and their arrangements in Figure 15 have been constructed from all the maps provided by the four stakeholder groups of teacher candidates, mentor teachers, teacher educators and policy makers. To understand what any single group thinks of the system, we need to go to the stakeholder-specific simplex system representations. Figure 15, in essence, is composed of four different nested simplex systems - each of which may be disentangled from this overall system representation. The same observations would hold true for a 3-D overall system representation constructed from all the maps. That is, it too would be a composite constructed from nested simplex systems. As a composite construction, it is interpretable but it is not helpful for understanding group or individual perceptions of system elements, their relationships, boundaries of influence, or possibilities of detecting and illustrating emergence. 


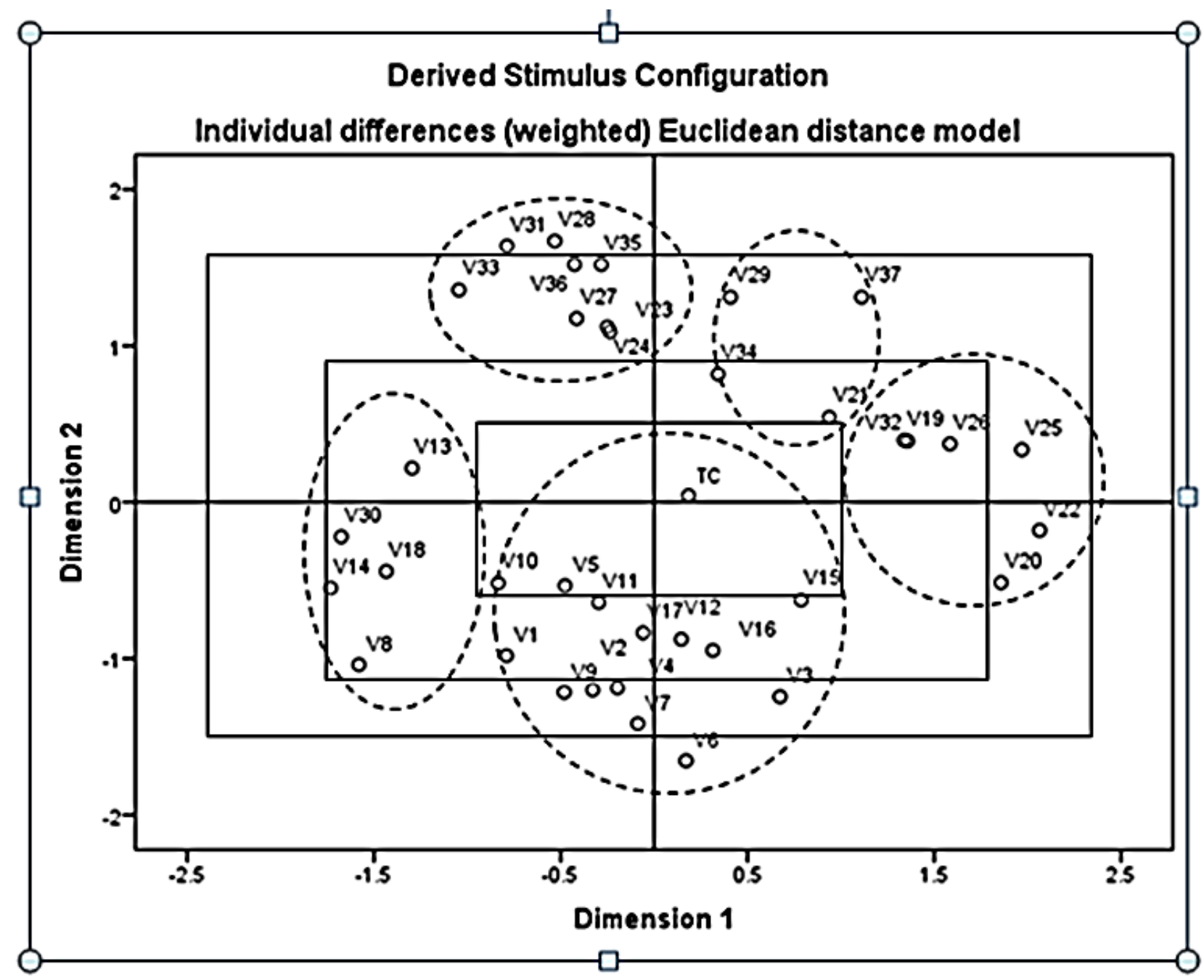

Figure 15: Two-dimensional representation of the initial teacher education overall consensus system

\section{Discussion}

Arguably the most pertinent goal of initial teacher education is producing well-prepared teachers. As we indicated at the beginning of this article, our research group works from the more specific assumption that the ultimate goal of initial teacher education is to prepare teachers who challenge inequities by enacting practice that promote all students' learning, including those traditionally marginalized by the system. Accomplishing this goal, however, may rest partially in understanding how stakeholder groups view and interact with one another within the complex system of teacher education. The objective of the present investigation, therefore, was to construct a data-gathering and analysis methodology for representing a complex system's structure as perceived by different stakeholder groups.

More specifically, we designed a series of linked iterative studies, each of which drew upon the results and limitations of the previous study to reveal more clearly how different stakeholder groups perceive the importance and interactions among system elements that they 
were most familiar with. The first study revealed perceptions of the strength of influence various system elements have on teacher candidates' learning to teach in ways that promote all children's learning. The second showed the extent to which those elements formed clusters of similarly perceived sources of influence while the third showed how those clusters were related to one another. The fourth study created multi-dimensional stakeholder-dependent "system consensus maps" that graphically illustrate Van Geert and Steenback's (2014) ideas about "simplex systems." The fifth study created a meta-complex system representation comprised of study four's stakeholder-dependent simplex systems.

Our overall design required an iterative process of defining and re-defining the data types and then proceeding through successively more complicated statistical procedures, each with its own form of results requiring different interpretive insights, all intended to build a systematically more comprehensive understanding and graphical representation of a system's structure, i.e., its elements and their relationships. Through this system mapping framework we established that different stakeholder constituencies perceived the complex system of ITE differently-perhaps because they know best the elements and processes that are proximal to their interests. The differences between the teacher candidate and teacher educator groups, particularly when framed as longitudinal change and transformation in the developmental progression of the educators, may be understood as not simply the addition or loss of new elements in the ITE system's structure but as changes in the perceived relational aspects of these attributes (Van Geert \& Steenback, 2014).

It is important to note that the physical nature of the mapping task was a limitation in this set of five studies. That is, the maps were initially constructed and arranged as rectangular images within which the participants placed words representing elements of the system. This means that a participant could have considered two elements to be of equally strong influence upon the teacher candidates' learning but because of the apparent border around the central location representing teacher candidates' learning (TC), the two elements could easily be placed at different distances from TC simply because the participant "stayed outside the lines" defining the TC location. This artificial restriction on the geometric space could be resolved if the mapping task consisted of a circular pattern of influence spaces around the TC location (similar to the pie-charts in Figures 5 and 6).

A second limitation of the mapping task was that placements were relatively static and fixed. Given that words representing elements of the system were written on sticky notes, they could be placed anywhere and then moved. However, once lines were drawn connecting the elements, participants did not rearrange the elements. This restriction can be resolved with system mapping software that generates circular diagrams and provides the opportunity for any type of re-arrangement of the elements. This software has been developed by the RITE team and has been pilot tested prior to large-scale administration in an upcoming new project. The mapping software has reduced both participant burden and measurement error and is capable of instantaneous computation of the inter-element distance matrix for each participant.

In conclusion we make three major points, which are different from one another but are also interrelated. Our first point is about complexity theory and research on teacher education. As we suggested at the beginning of this paper, a common approach in previous research about initial teacher education (and teachers' professional development) has been to simplify the 
problem of teacher learning and teacher education by focusing on one or more of its key parts without necessarily attending to how the parts are related to and influenced by other parts and factors. Along these lines, as we noted, Opfer and Pedder (2011) have proposed that instead of simplifying, researchers should conceptualize teachers' professional learning in terms of complex overlapping systems with the ultimate goal of developing explanatory theories based on patterns of interaction within and between levels of activity. Consistent with their proposal, a number of teacher education scholars have taken up a variety of approaches that resist simplification and reduction and instead try to account for multiple perspectives, nested contexts and processes, and non-linear relationships among the multitude of interacting system elements. These include, for example: ecological approaches (Zeichner, 2006), situated learning theory (Korthagen, 2010), structuration theory (Shilling, 2006), identity theories (Fairbanks et al, 2010; Korthagen, 2004), cultural-historical activity theory coupled with the associated ideas of expanded learning, hybridity and third spaces (Gutierrez \& Vossoughi, 2009; Gutierrez, Baquedano-Lopez \& Tejeda, 2009; Zeichner, 2006), and complexity theory (Davis \& Sumara, 1997, 2006; Cochran-Smith, et. al., 2014a,b). Although different from one another in important ways, all of these approaches have a common aim: to explain and account simultaneously for the complex and multiple factors that influence individual teacher candidates and the complex and multiple social contexts that structure teaching, learning and schooling - without being reductionist. Each approach foregrounds the holistic and complex nature of teaching in order to explain how and under what conditions aspects of initial teacher education influence teacher learning.

In this article, we have shown that complexity theory offers a number of important ideas and concepts that can be used for exploring aspects of teacher education when understood as a complex system. In particular we have used Van Geert and Steenbeck's (2014) notion of simplex systems in order to show the variations in structures that different constituency groups in teacher education derive to help them organize, understand and manage the complexity of the system in which they are participating. As Van Geert and Steenbeck suggest, differences in participants' simplex systems related to different understandings of priorities and practices may lead to conflicts and resistance among constituency groups. Knowing that different constituency groups are likely to perceive different frameworks for understanding and navigating the complex system of initial teacher education is a critically important insight for the creation and development in initial teacher education of the social, organizational, and intellectual contexts that support the emergence of teacher candidates' learning. Knowing in some detail the actual ways in which those simplex systems vary, especially those derived by teacher educators and teacher candidates, provides future research opportunities to specify the initial conditions that are likely to prompt the emergence in teacher candidates of key ideas and practices.

Our second point is that the quantitative complexity mapping approach we have taken here is relevant far beyond initial teacher education. This approach would also be useful more broadly in most areas of professional education where the point is to create the initial conditions that will prompt the emergence of critical ideas and practices to be taken up in the crucible of practice. In each of these areas of professional education, there are various constituency groups, including candidates for the profession, instructors who teach those candidates, mentors and 
other practitioners who demonstrate actions and reflect with candidates about what they are learning, and policy makers who are removed from the immediate learning context but whose policies often have far-reaching implications. This includes, for example, the complex systems of social work education, law enforcement education, counselor or therapist education, and education for the various allied health professions, such as nursing and other areas of medical practice. Just as we have shown for initial teacher education, all of these professional education fields can be understood as complex systems within which differently-positioned participants exposed to and interacting with a common set of actors and elements nonetheless derive differing simplex systems in order to carry out their respective functions. The nature of these simplex systems influences how the participants act and react as the overarching system learns and grows. In this way the simple systems are part of what needs to be understood before change can be initiated (Ell, et. al., in press). Koopmans (2014) suggests complexity approaches can be used to "analyze baseline conditions in (the) systems of interest" (p. 33) and that "discussions with participants about how they see their systems (as) being organized" (p.34) form an important part of such an analysis. As we have shown in great detail here, there are multiple ways to establish the baseline conditions.

Our final point has to do with the methods and methodology that are appropriate and consistent with complexity theory as a framework for understanding aspects of practice. Although many scholars in education and the social sciences have found complexity theory promising on a conceptual and descriptive level, there are multiple challenges involved in using it to guide the development and conduct of empirical studies that go beyond retrospective description (e.g., Horn, 2008; Morrison, 2008; Radford, 2006). This may explain why much of the previous work that has applied complexity theory to education has worked from a more or less metaphorical approach to complexity by engaging in "complexity thinking" about various educational contexts rather than empirical analysis and why we have relatively few explicit methodological discussions about complexity theory and research on teacher education. As others have noted, complexity theory does not offer a package of methods for data gathering and analysis. Indeed a number of theorists have emphasized that complexity theory is not method, but methodology (e.g., Haynes, 2008; Schneider \& Somers, 2006).

With respect to this last point, we show in great detail how our methodology drew on network and systems theory strategies to create a system mapping task designed to reveal the perceived major elements and their interdependencies and boundaries for the overarching ITE system associated with teacher preparation programs at the University of Auckland Faculty of Education. From simple frequency-counts to Procrustes-like vector projections through threedimensional geometric representations of simplex system element relationships, our iterative analysis strategies revealed different perceptions regarding the nature and functioning of localized simplex system structures. This iterative quantitative process uncovered similarities and differences between the teacher candidate and teacher educator hand-constructed system maps and made it very clear that there are different ways to understand the complex system of teacher education. For example, within the teacher candidate and teacher educator participants, perceptions of element influences varied, different clusters of element commonalities formed, boundaries between clusters varied, heterogeneity of individual participants was evident and statistically influential, dimensions of element cluster commonalities differed, and the 
emergence of a deeper understanding and practice of teaching was seen when teacher educators were portrayed as a future longitudinal stage in the development of initial teacher candidates. In fact, the results suggest that structural differences between stakeholder groups may be so strong that references to "an" initial teacher education system are probably misguided. That is, a representation of "a" system may be an over-generalization of a set of simplex systemsstakeholder specific systems united in their core elements but diverse in their structural relationships and all context dependent.

As described above, a complexity theory-based initial teacher education program and research model has been established at the University of Auckland. This opportunity has provided a foundation of support for plans and projects which are extensive, exciting and ambitious. For example, we are proactively planning and implementing a complexity theorybased research design intended to show changes in perceptions of system influences from initial entry into teacher preparation through graduation from the program, entry into teaching employment, mentoring and supervision of teachers, and finally as a teacher educator. This project is necessarily longitudinal and fraught with logistical challenges (Ludlow, Pedulla, Reagan, Enterline, Cannady, \& Chappe; 2011) but it has the potential to document and show group-level perspective and within-group heterogeneity, shifting between-group perceptions of influential elements and their boundaries and, ultimately, multifinality emergence as individuals grow and shape the system which, in turn, feeds back into the development of the next generation of teachers.

\section{References}

Aldenderfer, M.S., \& Blashfield, R.K. (1984). Cluster analysis. Sage University Paper series, no. 44. Beverly Hills: Sage Publications.

Browne, M.M. (1967). On oblique procrustes rotation. Psychometrika, 32, 125-132.

Byrne, D. (1998). Complexity theory and the social sciences. London and New York: Routledge.

Byrne, D., \& Callaghan, G. (2014). Complexity theory and the social sciences: the state of the art. Oxford: Routledge.

Cilliers, P. (1998). Complexity and postmodernism: understanding complex systems. London and New York: Routledge.

Clarke, A. \& Erickson, G. (2009). Cohort learning and complexity thinking: the case of the CITE teacher education programme. In Craig, C. \& Deretchin, L. (Eds.). Teacher learning in small-group settings. Teacher Education Yearbook XVII. New York: Roman and Littlefield.

Cochran-Smith, M., Ell, F., Ludlow, L.H., Grudnoff, L., \& Aitken, G. (2014). The challenge and promise of complexity theory for teacher education research. Teachers College Record, 116(5), 1-38.

Cochran-Smith, M., Ell, F., Grudnoff, L., Ludlow, L.H., Haigh, M., \& Hill, M. (2014). When complexity theory meets critical realism: a platform for research on initial teacher education. Teacher Education Quarterly, 41(1), 105- 122.

Cochran-Smith, M., \& Fries, K. (2005). The AERA panel on research and teacher education: context and goals. Studying teacher education. The report of the AERA panel on research and teacher education, 37-68.

Cochran-Smith, M., \& Villegas, A. M. (2014). Framing teacher preparation research: an overview of the field, Part 1. Journal of Teacher Education, 0022487114549072.

Cochran-Smith, M., \& Zeichner, K. (2005). Studying teacher education: the report of the AERA panel on research and teacher education. Mahwah, N.J.: Lawrence Erlbaum Associates.

Davis, B., Phelps, R., \& Wells, K. (2004). Complicity: an introduction and a welcome. Complicity: An International Journal of Complexity and Education, 1(1), 1-7.

Davis, B., \& Sumara, D. (1997). Cognition, complexity and teacher education. Harvard Educational Review. 67(1): 105-127.

Davis, B., \& Sumara, D. (2006). Complexity and education: inquiries in learning, teaching, and research. New York: Routledge. 
Davis, B., \& Sumara, D. (2007). Complexity science and education: reconceptualizing the teacher's role in learning. Interchange, 38(1), 53-67.

Davis, B., \& Sumara, D. (2010). "If things were simple ...": complexity in education. Journal of Evaluation in Clinical Practice, 16, 856-860.

Davis, B., Sumara, D., \& D'Amour, L. (2012). Understanding school districts as learning systems: some lessons from three cases of complex transformation. Journal of Educational Change, DOI 10.1007/s10833-012-9183-4.

Ell, F., Haigh, M., Cochran-Smith, M., Grudnoff, L., Ludlow, L., \& Hill, M. (In press). Mapping a complex system: What influences teacher learning during initial teacher education? Asia Pacific Journal of Teacher Education.

Everitt, B. (1974). Cluster analysis. London: Heinemann Educational Books Ltd.

Fels, L. (2004). Complexity, teacher education and the restless jury: pedagogical moments of performance. Complicity: An International Journal of Complexity and Education, 1(1), 73-98.

Grossman, P., \& McDonald, M. (2008). Back to the future: directions for research in teaching and teacher education. American Educational Research Journal, 45(1), 184-205.

Haggis, T. (2008). 'Knowledge must be contextual': some possible implications of complexity and dynamic systems theories for education research. In Mason, M. (Ed.). Complexity theory and the philosophy of education. Chichester, UK: Wiley-Blackwell.

Haynes, P. (2008). Complexity theory and evaluation in public management. Public Management Review, 10(3), 401-419.

Hess, F., \& McShane, M. (Eds.) (2014). Teacher quality 2.0: toward a new era in education reform. Cambridge, MA: Harvard Education Press.

Houchin, K., \& MacLean, D. (2005). Complexity theory and strategic change: an empirically informed critique. British Journal of Management, 16, 149-166.

IBM Corporation. (2013). IBM SPSS Statistics 22 Command Syntax Reference. Retrieved from:ftp://public.dhe.ibm.com/software/analytics/spss/documentation/statistics/22.0/en/client/Manuals/IB M_SPSS_Statistics_Command_Syntax_Reference.pdf.

Kowch, E. (2012). Towards leading diverse, smarter and more adaptable complex organizations. In Lewis, J. (Ed.) Technology as a tool for diversity leadership: implementation and future implications. New York, NY: IDEA Books.

Kruskal, J. B., \& Wish, M. (1978). Multidimensional scaling. Newbury Park, CA: Sage.

Kumashiro, K. K. (2015). Against common sense: teaching and learning toward social justice. New York, NY: Routledge.

Lorr, M. (1983). Cluster analysis for social scientists: techniques for analyzing and simplifying complex blocks of data. San Francisco, CA: Jossey-Bass, Inc.

Ludlow, L.H., Pedulla, J.J., Reagan, E.M., Enterline, S., Cannady, M. \& Chappe, S. (2011). Design

and implementation issues in longitudinal research. Educational Policy Analysis Archives. North America, 19, apr. 2011. Available at: http://epaa.asu.edu/ojs/article/view/802/906.

Mason, M. (Ed.) (2008). Complexity theory and the philosophy of education. West Sussex: Wiley Blackwell.

Morrison, K. (2008). Educational philosophy and the challenge of complexity theory. In Mason, M. (Ed.), Complexity Theory and the Philosophy of Education (pp. 16-31). West Sussex: Wiley Blackwell.

Nielson, W., Triggs, V., Clarke, A., \& Collins, J. (2010). The teacher education conversation: network of cooperating teachers. Canadian Journal of Education, 33(4), 837-868.

Opfer, V. D., \& Pedder, D. (2011). Conceptualizing teacher professional learning. Review of Educational Research, 81(3), 376-407.

Pratt, S. S. (2011). Emerging changes in teacher education. Complicity: An International Journal of Complexity and Education, 8(1).

Radford, M. (2006). Researching classrooms: Complexity and chaos. British Educational Research Journal, 32(2), 177-190.

Reynolds, S. (2011). Gaps in the system. Complicity: An International Journal of Complexity and Education, 8(1), 28-31. 
Ruiz-Primo, M., \& Shavelson, R. (1996). Problems and issues in the use of concept maps in science assessment. Journal of Research in Science Teaching, 33(6), 569-600.

Schneider, M., \& Somers, M. (2006). Organizations as complex adaptive systems: implications of complexity theory for leadership research. The Leadership Quarterly, 17(4), 351-365.

Shepard, R.N., Romney, A.K., \& Nerlove, S.B. (1972). Multidimensional scaling: theory and applications in the behavioral sciences. Volume I. London: Seminar Press.

Sumara, D., \& Davis, B. (1997). Enactivist theory and community learning: toward a complexified understanding of action research. International Journal of Educational Action Research, 5(3), 403-422.

Sumara, D., \& Davis, B. (2009). Complexity theory and action research. In Somekh, B. and Noffke, S. (Eds.), Handbook of Educational Action Research. Thousand Oaks, CA: Sage Publications, 358-369.

Takane, Y., Young, F. W., \& de Leeuw, J. (1977). Nonmetric individual differences multidimensional scaling: an alternating least squares method with optimal scaling features. Psychometrika, 42, 7-67.

Thurstone, L.L. (1947). Multiple Factor Analysis. Chicago: University of Chicago Press.

United States Department of Education (2009). Teacher preparation: Reforming the uncertain profession-remarks of secretary Arne Duncan at Teachers College, Columbia University. Retrieved Dec. 28, 2014, from http://www2.ed.gov/news/speeches/2009/10/10222009.html.

United States Department of Education (2011). Preparing and credentialing the nation's teachers. Office of Postsecondary Education: Washington DC.

Waks, L. (2011). Teacher education programs as complex organizations. Emerging changes in teacher education, 8(1), 65-69. Young, F. W. (1987). Multidimensional scaling: history, theory, and applications. Hillsdale, NJ: Lawrence Erlbaum Associates.

\section{Appendix - Software syntax}

(a) SPSS syntax for cluster analysis procedure for linkages

PROXIMITIES v1 v2 v3 v4 v5 v6 v7 v8 v9 v10 v11 v12 v13 v14 v15 v16 v17 v18 v19 v20 v21

v22 v23 v24 v25 v26 v27 v28 v29 v30 v31 v32 v33 v34 v35 v36 v37

/MATRIX OUT('C: \Users \ludlow $\backslash$ AppData \Local $\backslash$ Temp $\backslash$ spss4044 \spssclus.tmp')

/VIEW=VARIABLE

/MEASURE=PH2

/PRINT NONE

/MISSING=INCLUDE

/STANDARDIZE=VARIABLE NONE.

CLUSTER

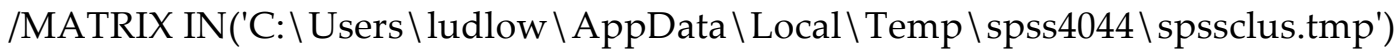

/METHOD SINGLE

/PRINT SCHEDULE

/PRINT DISTANCE

/PLOT DENDROGRAM.

b) SPSS syntax for cluster analysis procedure for distances

CLUSTER TC, V1 TO V37 
/MATRIX=IN $\left(^{*}\right)$
/METHOD MEDIAN
/PRINT SCHEDULE
/PRINT DISTANCE
/PLOT DENDROGRAM.

c) SPSS syntax for multidimensional scaling procedure-linkages

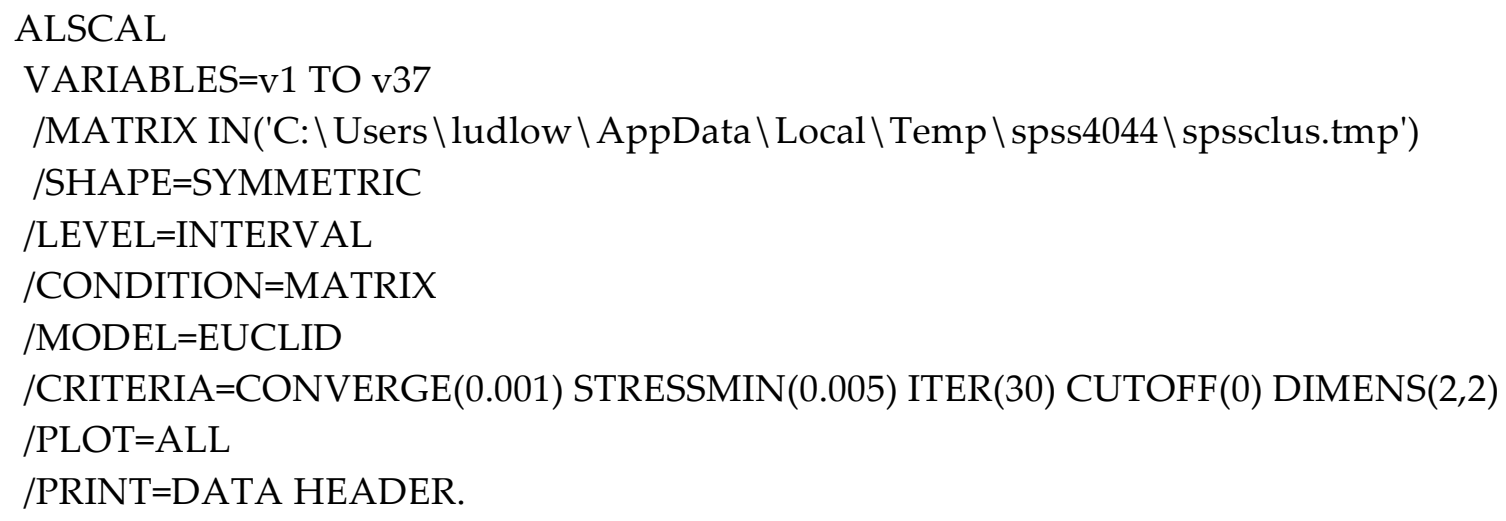

d) SPSS syntax for multidimensional scaling procedure-distances

\section{ALSCAL}

VARIABLES=TC V1 V2 V3 V4 V5 V6 V7 V8 V9 V10 V11 V12 V13 V14 V15 V16 V17 V18 V19

V20 V21 V22 V23 V24 V25 V26 V27 V28 V29 V30 V31 V32 V33 V34 V35 V36 V37

/SHAPE=SYMMETRIC

$/$ LEVEL=RATIO

/CONDITION=MATRIX

/MODEL=EUCLID

/CRITERIA=CONVERGE(0.001) STRESSMIN(0.005) ITER(30) CUTOFF(0) DIMENS(2,3)

/PLOT=DEFAULT ALL

/PRINT=HEADER.

\section{Acknowledgments}

Portions of this paper were presented at the annual meetings of the American Educational Research Association, Philadelphia, PA April 7, 2014 and San Francisco, CA April 30, 2013.

\section{About the Authors}

Larry Ludlow is Professor and Chair of the Department of Educational Research, Measurement and Evaluation in the Lynch School of Education at Boston College, USA. He teaches courses in research methods, applied statistics, and psychometric theory and practice. His research interests include longitudinal models for faculty course evaluations, Rasch model instrument development applications, and teacher retention and attrition models. His consulting collaborations include the U.S. Department of Education, Office of Indian Education; 
Center for Psychiatric Rehabilitation, Boston University; St. Patrick's College, Dublin, Republic of Ireland; and Higher School of Economics, Moscow, Russia. ludlow@bc.edu

Fiona Ell is a senior lecturer in the Faculty of Education at the University of Auckland, New Zealand. Her research interests include professional learning for teachers and mathematics education, especially in preservice teacher education. She has worked with schools as they try to improve outcomes for learners as well as with teacher candidates as they learn to be teachers who can make a difference for all students, particularly those who are marginalised. Recent publications include exploring complexity theory as a way to understand learning to teach and an examination of how mentor teachers judge teacher candidates' readiness to teach. She is currently part of two research teams, one looking at the promotion of equity through initial teacher education and one looking at adaptive expertise in facilitation. f.ell@auckland.ac.nz

Marilyn Cochran-Smith is the Cawthorne Professor of Teacher Education for Urban Schools and Director of the Ph.D. Program in Curriculum and Instruction at the Lynch School of Education, Boston College. A teacher education scholar and practitioner for more than 30 years, Cochran-Smith is a frequent presenter nationally and internationally and is widely known for her work about teacher education research, practice and policy. Dr. Cochran-Smith has written nine books, five of which have won national awards and recognitions, and more than 200 articles, chapters, handbook chapters, and editorials on teacher education research, practice and policy, social justice, and practitioner research. cochrans@bc.edu

Avery Newton is a Doctoral Candidate in the Department of Educational Research, Measurement, and Evaluation in the Lynch School of Education at Boston College. Her research centers on exploring the academic and affective correlates in the education-workforce transition. She is primarily training as a quantitative methodologist, with additional interests in evaluation, policy, survey design and analysis, and large-scale data analysis. newtonav@bc.edu

Kaitlin Trefcer is a fourth grade teacher and graduate of the Lynch School of Education at Boston College, USA. Kaitlin received her undergraduate degree in Elementary Education and her master's degree in Educational Research, Measurement and Evaluation. Her research interests include teacher education programs, teacher evaluation and classroom assessment. ktref17@gmail.com

Kelsey Klein is a Doctoral Candidate in the Department of Educational, Research, Measurement, and Evaluation in the Lynch School of Education at Boston College, USA. Her dissertation research is focused on factors contributing to doctoral degree completion and program attrition. Her research interests include instrument development, models for student success, and teacher evaluation models. kleinkg@bc.edu

Lexie Grudnoff is an Associate Professor of the School of Teaching, Learning and Professional Development in the Faculty of Education and Social Work at The University of Auckland, New Zealand. She teaches courses in practitioner research methods, mentoring and professional development and supervises postgraduate student research in areas related to initial teacher education and beginning teaching. Her research areas are broadly related to teacher professional learning and development, in particular developing understandings about how to enact practice that leads to more equitable learner outcomes and opportunities. 1.grudnoff@auckland.ac.nz

Mavis Haigh is an Associate Professor, School of Learning, Development and Professional Practice at The University of Auckland, New Zealand. Her research interests include professional/clinical practice in Initial Teacher Education, especially the role of partnership between the university and schools and early childhood centers; the work of teacher educators; and science teacher education. As a monitor for the Education Council of Aotearoa New Zealand she reviews initial teacher education programs across the country.

m.haigh@auckland.ac.nz 
Mary F. Hill is an Associate Professor, Deputy Head of School of Learning, Development and Professional Practice in the Faculty of Education and Social Work at The University of Auckland, New Zealand. Her work is grounded in the context of contemporary schooling and teacher education and the contribution that quality teaching makes to a socially just society. Her research interests include educational assessment, assessment education for pre- and in-service teachers, practitioner inquiry and the use of complexity theory and critical realism as explanatory theory for rethinking teacher education for equity. mf.hill@auckland.ac.nz

(c) Copyright 2017. The authors, Larry Ludlow, Fiona Ell, Marilyn Cochran-Smith, Avery Newton, Kaitlin Trefcer, Kelsey Klein, Lexie Grudnoff, Mavis Haigh and Mary F. Hill, assign to the University of Alberta and other educational and non-profit institutions a non-exclusive license to use this document for personal use and in courses of instruction provided that the article is used in full and this copyright statement is reproduced. The authors also grant a non-exclusive license to the University of Alberta to publish this document in full on the World Wide Web, and for the document to be published on mirrors on the World Wide Web. Any other usage is prohibited without the express permission of the authors. 